\title{
LA GRAN DEPRESIÓN Y EL FRACASO PERUANO. BALANCE DE LA PRIMERA OLA DEL CORONAVIRUS
}

\section{THE GREAT DEPRESSION AND THE PERUVIAN FAILURE. BALANCE OF THE FIRST WAVE OF THE CORONAVIRUS}

\author{
Juan De la Puente Mejia \\ Director del Fondo Editorial USMP \\ Orcid: 0000-0002-6302-497X \\ https://doi.org/10.24265/voxjuris.2021.v39n2.11 \\ kotoshperu@gmail.com \\ Perú
}

\section{SUMARIO}

- Introducción.

- El marco conceptual.

- El fracaso peruano.

- Agendas y actores de la gran depresión.

- La respuesta peruana.

- Razones y tendencias del fracaso.

- Conclusiones.

- Fuentes de información .

\section{RESUMEN}

El trabajo aborda la gran depresión y el fracaso peruano ante la pandemia del Covid-19 en la etapa comprendida entre marzo de 2020 y enero de 2021, a partir de su impacto en el Estado y en la sociedad, las brechas ocurridas entre ambos, y la interacción entre la pandemia y los fenómenos asociados a ella, como la crisis económica y la crisis política registrados en una etapa extremadamente crítica. En el período abordado no se había hecho presente el escándalo de las vacunas, "vacunagate", denunciado a inicios del mes de febrero de 2021.

\section{ABSTRACT}

The work addresses the great depression and the Peruvian failure in the face of the Covid-19 pandemic in the stage between March 2020 and January 2021, based on its impact on the State and on society, the gaps that occurred between the two, and the interaction between the pandemic and the phenomena associated with it, such as the economic crisis and the political crisis registered at an extremely critical stage. In the period covered, the vaccine scandal, "vaccinate", denounced at the beginning of February 2021, had not been present.

\section{PALABRAS CLAVE}

Pandemia, Covid-19, coronavirus, primera ola, ciclos, microciclos, respuesta pública, gran depresión, cuarentena, estado de emergencia, crisis, pobreza.

\section{KEYWORDS}

Pandemic, Covid-19, coronavirus, first wave, cycles, microcycles, public response, great depression, quarantine, state of emergency, crisis, poverty.

\section{INTRODUCCIÓN}

El presente trabajo aborda la gran depresión $\mathrm{y}$ el fracaso peruano ante la pandemia del Covid-19 entre los meses de marzo de 2020 y enero 2021, a partir de su impacto en el Estado y en la sociedad, las brechas ocurridas entre ambos, y la interacción entre la pandemia y los fenómenos asociados a ella, como la crisis económica y la crisis política registrados en una etapa extremadamente crítica. En el período abordado no se había hecho presente el problema moral que implicó el escándalo de las vacunas, "vacunagate", denunciado a 
inicios del mes de febrero de 2021, aun cuando a los citados fenómenos le son inherentes innegables cuestiones morales.

La pandemia fue desde el inicio una doble experiencia trágica; al dolor y miedo de la pandemia como hecho colectivo y nacional se agregaron la épica de la primera línea y la realidad que se impuso a un país que olvidó oficialmente sus brechas históricas, poseído por la contemplación de un crecimiento cierto e innegable, pero incompleto. En poco menos de 30 días se licuaron 18 años de auge económico y (re) emergió un cuadro inclemente que la elite peruana negaba de palabra, obra y omisión.

El pasado es menos pasado. Los costos inmediatos de la pandemia no son nuevos, es la irrupción de una reiteración cubierta por la alfombra tendida por el relato ideológico oficial de un país que se resistió durante esos 18 años a las agendas de igualdad, inclusión y reforma política. No obstante, en los efectos de la pandemia habita menos un determinismo biológico que considera inútil toda resistencia al virus o un fatalismo estructural que hace definitorio el abandono de las políticas sociales, y alberga más un grupo de acciones y negligencias que colocan este drama sobre una escena dominada por la calidad e intensidad de las políticas públicas y los liderazgos en esta etapa.

La búsqueda de los males en el pasado como razón excluyente puede ser un riesgoso pasaje a la inmunidad e impunidad de las políticas públicas deficitarias y sus responsables. En ese punto, el análisis del fracaso peruano es desafiante porque debe abrirse paso entre explicaciones incompletas. Lo sucedido en el Perú entre marzo de 2020 y enero de 2021, una gran depresión -entendida como un proceso profundamente crítico, de rápida formación $\mathrm{y}$ del que forman parte varias crisis- hace insuficiente cualquier medición exclusiva de la pandemia que pretenda ser representativa de la situación general ${ }^{1}$. Con tal propósito, el estudio considera crucial la elaboración de un marco conceptual para el acercamiento a este proceso,

1 Es el caso del estudio del Instituto Lowy de Sydney (Australia) que en enero de 2021 publicó un índice denominado Covid Perfomance Index, con información de 100 países cuyo desempeño fue evaluado a partir de seis indicadores: casos confirmados, número de muertes, casos por millón, muertes por millón, casos confirmados en relación a las pruebas y pruebas por mil personas. https://interactives. lowyinstitute.org/features/covid-performance/ para lo cual se define su interdependencia, las variables que permiten una mejor observación, y su periodización.

La existencia de fenómenos de muy rápida sucesión es la constante de la pandemia del Covid-19; son pequeños ciclos a los que corresponden o deberían corresponder una agenda pública, un temperamento de la sociedad y algunas veces una forma de respuesta del Estado o un vacío respecto a las expectativas de los peruanos. La falta de reciprocidad entre estos elementos ofrece una realidad que no puede ser ignorada en su especificidad, que no la empobrece y que, al contrario, responde a las preguntas sobre la respuesta peruana en los ámbitos estudiados.

\section{EL MARCO CONCEPTUAL}

\section{E1 acercamiento de la pandemia. E1 método.}

Las explicaciones del fracaso peruano ante la pandemia, nos remite al método para acercarnos a su temática, y especialmente a su interdependencia. El Covid-19 dejó de ser inmediato un asunto exclusivo de la salud para convertirse en un problema trasversal de la sociedad, de carácter internacional por su origen $\mathrm{y}$, en esa etapa, por sus soluciones. La sexta reunión del Comité de Emergencias de la Organización Mundial de la Salud (OMS) realizada en Ginebra (Suiza) el 14 de enero de 2021 ratificó que la pandemia del coronavirus sigue constituyendo un hecho de carácter extraordinario y un riesgo en salud pública para los demás estados debido a su propagación internacional, y que continúa exigiendo una respuesta igualmente internacional coordinada en condición de Emergencia de Salud Pública de Importancia Internacional (ESPII) ${ }^{2}$.

No es nuevo el reconocimiento de la interdependencia de lo que atañe a la salud. Años atrás, el concepto de salud fue objeto de redefiniciones (Salud UIS, 2014), dejando de lado aquella de la Organización Mundial de la Salud (OMS) de 1946 según la cual era "un estado de completo bienestar físico, mental y social, y no solamente la ausencia de

\footnotetext{
2 https://www.who.int/es/news/item/15-01-2021statement-on-the-sixth-meeting-of-the-internationalhealth-regulations-(2005)-emergency-committee-regardingthe-coronavirus-disease-(covid-19)-pandemic
} 
enfermedad ya es un asunto del pasado", con un nuevo énfasis en los factores que actúan sobre ella, es decir "un estado de bienestar emergente de las interacciones entre los potenciales de los individuos, las demandas de la vida y los determinantes sociales y ambientales" (Idem).

De acuerdo a este razonamiento, el análisis de la pandemia resulta insuficiente si propugna una mirada exclusiva de los contagios, mitigación, atención hospitalaria y fallecimientos. En el caso peruano, la pandemia disparó una crisis económica inédita por su profundidad y por la rapidez de su formación, impactó sobre la crisis política que "encontró" en su camino y se trasformó en una crisis de instituciones y de régimen político. No es un destino casual; en tiempos de plagas, la palabra emergencia recupera su doble sentido, tanto como urgencia de responder a todas las crisis desatadas por la pandemia, como por las antiguas exclusiones y abandonos (Velásquez, 2020).

\section{La gran depresión}

Se aprecia que, en el período citado, el Perú fue objeto del surgimiento de un vasto proceso crítico que empequeñece categorías tradicionales como "crisis". El reconocimiento de varios fenómenos críticos profundos y concurrentes permiten el uso de la denominación "gran depresión" para resumirlos y agregarlos. Estos fenómenos son por lo menos seis: 1) la muerte de decenas de miles de peruanos en un corto período de tiempo, 40 mil al 31 de enero 2021 según las cifras oficiales de la pandemia, pero más de 100 mil si se consideran otras bases de datos de origen oficial $^{3}$; 2) la crisis económica que acabó con los 18 años de auge del crecimiento económico para producir una caida del $-11.5 \%$ del PBI en 2020 según las previsiones del Banco Central de Reserva $(\mathrm{BCR})^{4}$; 3) la agresiva y rápida destrucción del empleo formal e informal, que en la capital llevó a la pérdida de más de 1.13 millones de empleos en $2020^{5}$; 4) el retroceso de la pobreza y de

3 Son los datos del año 2020 del Repositorio Único Nacional de Información en Salud (REUNIS), del Sistema Informático Nacional de Defunciones (SINADEF) y del Centro Nacional de Epidemiologia del Ministerio de Salud.

4 https://www.bcrp.gob.pe/docs/Publicaciones/ Reporte-Inflacion/2020/diciembre/reporte-de-inflaciondiciembre-2020.pdf

5 https://www.inei.gob.pe/media/MenuRecursivo/ boletines/01-informe-tecnico-mercado-laboral-oct-novdic-2020.pdf la pobreza extrema e inseguridad alimentaria que afectó en mayo de 2020 a por lo menos 3.5 millones de peruanos $\left.{ }^{6} ; 5\right)$ la irrupción de crisis humanitarias en territorios y sectores, como en las mujeres por violencia familiar, pueblos originarios o personas privadas de su libertad; y 6) la precariedad de los poderes públicos, el agravamiento de la confrontación política y las salidas ilegales o muy controversiales.

La gran depresión alude a una excepcionalidad profunda en la que los procesos críticos colisionan entre sí, se alejan o se superponen, una dinámica donde las crisis "grandes", como la de la salud, economía, seguridad y acceso alimentario, invisibilizan a las más "pequeñas", como la del transporte urbano, el desplazamiento interno, la educación pública y de los pueblos originarios, entre otros.

\section{Variables de desempeño}

La evolución desigual de las crisis que forman la gran depresión conducen a variables que permiten una observación adecuada del desempeño del Estado y la evolución de la sociedad en esta situación excepcional. Sobre lo primero, es tradicional la dificultad de medir la eficacia de las políticas públicas en el corto plazo, aunque es posible hacerlo en el mediano plazo a través de los indicadores del desempeño de políticas públicas ${ }^{7}$. Sobre la sociedad, se tiene algunos estudios realizados en los últimos meses $^{8}$, y mediciones de la empresas encuestadoras, especialmente las de mayor regularidad, Ipsos Perú e Instituto de Estudios Peruanos (IEP). No obstante, el desempeño del Estado en un período de crisis y cambios acelerados en un período muy corto de tiempo, obliga a establecer parámetros de observación, inherentes a la magnitud de lo ocurrido. Estos son: capacidad y deliberación, acatamiento y resiliencia, políticas de emergencia y bienes públicos:

6 Estudio de mayo 2020 del Programa Mundial de Alimentos de las NNUU. https://www.mesadeconcertacion.org.pe/ storage/documentos /2020-08-17/reporte-seguridadalimentaria-y-nutricional-3107-final.pdf

7 CEPLAN, El Peru en los indicadores mundiales. https:// www.ceplan.gob.pe/wp-content/uploads / 2016/08/ INDICADORES_MUNDIALES_2016.pdf

8 Entre los estudios nacionales sobre la evolución de la sociedad durante la pandemia se tiene varios capítulos del informe Democracia, derechos humanos y emergencia. Miradas a la respuesta del Estado a la pandemia, del IDHEPUCP; y los informes Impactos de la epidemia del coronavirus en el trabajo de las mujeres en el Perú; y Covid-19 y el shock externo: Impactos económicos y opciones de política en el Perú, ambos del PNUD Perú, entre otros. 
i) Capacidad y deliberación. Acción política del Gobierno y del Estado. Incluye el respaldo a las decisiones del Gobierno Central y los gobiernos subnacionales, la legitimidad de las mismas, el manejo de la agenda pública en relación a otros actores, la rapidez de los ajustes y las rectificaciones, y las relaciones del Gobierno con los poderes y los medios, y el desempeño de estos poderes distintos al Ejecutivo.

ii) Acatamiento y resiliencia. Acatamiento de las restricciones $u$ otras medidas de emergencia, la adaptación y respuesta a los efectos de la gran depresión y la vigencia del orden público. Incluye el cumplimiento de las medidas excepcionales dictadas, la tolerancia y resiliencia de la sociedad a las incomodidades y privaciones que impone la emergencia, y la vigencia de los DDHH.

iii) Políticas de emergencia. Capacidad ejecutiva del Gobierno y del Estado. Incluye la implementación de las medidas por el Gobierno Central, los gobiernos subnacionales y los organismos constitucionales autónomos; el financiamiento, oportunidad y eficacia de la prestación de servicios de salud y educación, especialmente las demandas hospitalarias; la eficacia de las políticas de mitigación de la pandemia; el subsidio a los sectores vulnerables y la solución a las crisis humanitarias ocasionadas por la pandemia; las medidas de apoyo a la reactivación de la economía; y el funcionamiento de los sectores esenciales.

iv) Bienes públicos. Abastecimiento de los otros bienes públicos. Incluye la disponibilidad de alimentos de primera necesidad y el acceso a ellos, y la prestación de los servicios de energía, transporte, agua potable y comunicaciones; el funcionamiento de los servicios municipales, servicios bancarios y financieros, y de justicia.

\section{Los ciclos y microciclos.}

Por otro lado, la pandemia es un proceso sujeto a una sucesión de eventos dependen de la capacidad de gestión del Estado y de fenómenos a menudo fuera del control de este. El ejercicio de agregación y desagregación de los hechos debe considerar los cambios acelerados que presentan coyunturas cortas; estas se sucedieron con agendas propias entre marzo y mayo de 2020 como microciclos, para luego pasar a un período más largo -un cicloentre julio y octubre de 2020, para retornar a los microciclos a raíz de la destitución del presidente Vizcarra (noviembre 2020), un momento donde todas las crisis parecieron condensarse en lo político, para retomar su naturaleza más plural en enero con la formación de la segunda ola de contagios y la cuestión de la vacuna.

Momentos previos. En la periodización de la pandemia en el Perú debe considerarse los momentos previos en su evolución global: 1) el inicio, su localización china, entre diciembre de 2019 y enero de 2020 ; 2) la expansión europea y asiática, entre enero y febrero de 2020 hasta cuando la OMS, declaró al Covid-19 una Emergencia Sanitaria de Preocupación Internacional al haberse extendido a 15 países; y 3) la declaración de pandemia el 11 de marzo, cuando la OMS la declaró como tal, con lo que se inicia el aislamiento global. El 26 de marzo de 2020 se tenían 500 mil casos en el mundo, en tanto que el inicio de la emergencia en el Perú se sitúa el 11 de marzo de 2020 y la declaración de la cuarentena el 15 de marzo de 2020.

La sucesión de microciclos políticos fue más intensa entre marzo y mayo de 2020, para arribar a un ciclo largo entre los meses de junio y octubre. Entre noviembre, la gran depresión peruana vuelve a experimentar nuevos microciclos.

i) Primer microciclo, entre la segunda y cuarta semana de marzo de $\mathbf{2 0 2 0}$. En esta etapa se registra una alta capacidad de acción política del Gobierno y debilidades de los gobiernos regionales y locales. Se aprecia el manejo de la agenda por parte del Gobierno sin resistencia de los otros sectores, y el acatamiento diferenciado de la cuarentena. Se aprecia también una capacidad intermedia en la implementación de las medidas del Gobierno contra la pandemia y en cambio una capacidad baja en el nivel regional y local. En este microciclo se anuncian subsidios a sectores vulnerables.

ii) Segundo microciclo, primera y segunda semana de abril de 2020. Alta capacidad 
de acción política del Gobierno, pero débil en las regiones y municipios; se advierte una capacidad intermedia en la ejecución de las medidas y problemas en la gestión de las pruebas de descarte. Se inicia la presión sobre los servicios de cuidados intensivos; se paga del primer bono; se lleva a cabo acciones de apoyo a las empresas, y se registra presiones de las grandes empresas por lograr una mayor flexibilización laboral.

iii) Tercer microciclo, tercera y cuarta semana de abril de 2020 . Se experimenta una baja capacidad de acción política del Gobierno, con dificultades internas para extender la cuarentena. Se observa que las regiones y municipios realizan una actividad deficitaria frente a la pandemia, en tanto que la agenda pública tiene un manejo compartido entre el Gobierno, los medios y el Congreso. No obstante, se deteriora el consenso entre los poderes públicos por el silencio del gobierno ante la Ley del retiro del $25 \%$ de aportes a las AFP. Se diluye la respuesta peruana contra el Covid-19; y se forman varias crisis humanitarias: Piura, Lambayeque y Loreto, en las cárceles (500 internos y 113 trabajadores penitenciarios contagiados al 22 de abril de 2020), y se produce el retorno de los desplazados internos (casi 200 mil inscritos en las listas de retornantes al 28 de abril de 2020).

iv) Cuarto microciclo, mayo de 2020. Baja capacidad de acción política del Gobierno frente a la pandemia con dificultades para extender la cuarentena; reducción de la aprobación ciudadana a las medidas. En esta etapa progresa el desborde de la cuarentena (el 7 de mayo, el ministro del Interior indicó que el incumplimiento de la cuarentena alcanzaba al $40 \%$ ), aumentan las denuncias de violencia familiar (al 4 de mayo el Ministerio de la Mujer revela 23,194 consultas telefónicas de ayuda y 11 feminicidios durante la cuarentena); y la afectación de la pandemia a la Policía Nacional (al 7 de mayo de 2020 se reportaban 3,873 policías contagiados y 46 fallecidos). Se agravan las crisis humanitarias, se inicia la reapertura de la economía, el pago de los bonos rural y a trabajadores independientes, y se anuncia al primer el Bono Universal Familiar. El presidente reúne el Acuerdo Nacional, se interrumpe el consenso general de los poderes del Estado y algunos ministerios presentan flancos abiertos. Se agota el discurso oficial y se inicia una deliberación con pérdida de iniciativa del Gobierno. La agenda pública se encuentra en disputa.

\section{Ciclo largo junio-octubre de 2020.}

El período junio-octubre presenta el fin de los microciclos y el establecimiento de un ciclo largo caracterizado por un crecimiento lineal de casos, empezando el ciclo en 155 mil. Cuando el presidente Vizcarra acude al Congreso para su mensaje del 28 de julio suman 390 mil casos. En este ciclo se normaliza el uso de la meseta para definir la evolución del virus, culmina de modo formal la cuarentena (30 de junio) y se consolida la reactivación de la economía como la única certeza pública. El Estado se reabre con retraso, se activa la tensión entre el Gobierno y el Congreso y se definen las opciones al interior del gabinete que culmina con el cambio del mismo ( 15 de julio) y un nuevo cambio (6 de agosto) luego de que el gabinete Cateriano no recibiera la confianza del Congreso. En este período se registra el primer colapso de los servicios de salud, se interviene el sistema de salud de algunas regiones, se muestran los límites del Gobierno para rehacer el "modelo" perdido en mayo, se hace patente la falta de oxígeno, y se sinceran las muertes por el Covid-19. A fines de agosto, el Perú tenía, proporcionalmente, la cifra más alta de muertos por Covid-19: más de 28 mil, una tasa de mortalidad de 85.8 fallecidos por cada 100 mil habitantes y 625 mil casos. El 30 de octubre los muertos superaron los 34 mil, oficialmente, y los casos los 900 mil. El Estado no puede imponer su política a las clínicas privadas sobre el costo de la atención ${ }^{9}$, el Gobierno se debilita ante un Congreso y la Fiscalía investiga al presidente por corrupción. El país carece de agenda, pero se evidencia la resiliencia de los peruanos frente a las crisis.

9 https://www.bbc.com/mundo/noticias-americalatina-53185216 


\section{Cuadro 1. Microciclos y ciclo largo de la pandemia marzo-octubre 2020}

\begin{tabular}{|c|c|c|c|c|c|}
\hline $\begin{array}{l}\text { MICROCICLOS } \\
\text { Y CICLO }\end{array}$ & $\begin{array}{c}\text { Capacidad de } \\
\text { comunicación del } \\
\text { Gobierno y manejo de } \\
\text { la agenda }\end{array}$ & $\begin{array}{c}\text { Acatamiento de } \\
\text { la emergencia y } \\
\text { vigencia de DDHH }\end{array}$ & $\begin{array}{c}\text { Capacidad ejecutiva } \\
\text { del Gobierno y el } \\
\text { Estado }\end{array}$ & $\begin{array}{l}\text { Abastecimiento y } \\
\text { servicios }\end{array}$ & Agenda pública \\
\hline $\begin{array}{l}\text { 1er microciclo } \\
2^{\mathrm{a}}, 3^{\mathrm{a}} \text { y } 4^{\mathrm{a}} \text { semanas } \\
\text { marzo }\end{array}$ & $\begin{array}{l}\text { Alta capacidad de } \\
\text { acción política del } \\
\text { Gobierno; manejo } \\
\text { de la agenda sin } \\
\text { resistencia. }\end{array}$ & $\begin{array}{l}\text { Acatamiento } \\
\text { diferenciado de la } \\
\text { cuarentena. }\end{array}$ & $\begin{array}{l}\text { Capacidad intermedia } \\
\text { de ejecución de las } \\
\text { medidas del Gobierno. } \\
\text { Bono, "Quédate en } \\
\text { casa" }\end{array}$ & $\begin{array}{c}\text { Alimentos } \\
\text { disponibles; } \\
\text { prestación regular de } \\
\text { servicios. }\end{array}$ & $\begin{array}{l}\text { Unitaria: la } \\
\text { pandemia. }\end{array}$ \\
\hline $\begin{array}{l}2^{\circ} \text { microciclo } \\
\text { 1a y } 2^{\mathrm{a}} \\
\text { semanas abril }\end{array}$ & $\begin{array}{l}\text { Alta capacidad de } \\
\text { acción política del } \\
\text { Gobierno; amplio } \\
\text { manejo de la agenda. }\end{array}$ & $\begin{array}{l}\text { Mayor acatamiento } \\
\text { de la cuarentena; } \\
\text { desorganización } \\
\text { en los centros de } \\
\text { abastos de alimentos. }\end{array}$ & $\begin{array}{l}\text { Problemas en gestión } \\
\text { de pruebas; inicio } \\
\text { de la presión sobre } \\
\text { los servicios UCI. } \\
\text { Escalada en regiones. } \\
\text { Bono independiente. }\end{array}$ & $\begin{array}{c}\text { Alimentos } \\
\text { disponibles; } \\
\text { prestación regular de } \\
\text { servicios. }\end{array}$ & $\begin{array}{c}\text { Dual: pandemia y } \\
\text { empleo/ingreso. }\end{array}$ \\
\hline $\begin{array}{l}\text { 3er microciclo } \\
\text { 3a y } 4^{\text {a }} \text { semana } \\
\text { abril }\end{array}$ & $\begin{array}{c}\text { Baja capacidad de } \\
\text { acción política del } \\
\text { Gobierno; dificultades } \\
\text { internas para extender } \\
\text { la cuarentena. Manejo } \\
\text { compartido de la } \\
\text { agenda. }\end{array}$ & $\begin{array}{l}\text { Reducción del } \\
\text { acatamiento de } \\
\text { la cuarentena; } \\
\text { dificultades } \\
\text { para extender la } \\
\text { cuarentena. }\end{array}$ & $\begin{array}{l}\text { Se diluya el "modelo } \\
\text { peruano" contra } \\
\text { el COVID-19; } \\
\text { formación de crisis } \\
\text { humanitarias. } \\
\text { Desplazados internos. }\end{array}$ & $\begin{array}{c}\text { Alimentos } \\
\text { disponibles; } \\
\text { prestación regular de } \\
\text { servicios. }\end{array}$ & $\begin{array}{l}\text { Plural: pandemia, } \\
\text { empleo/ingreso, } \\
\text { educación, } \\
\text { desplazados, } \\
\text { violencia, crisis } \\
\text { humanitarias, } \\
\text { fondos AFP. }\end{array}$ \\
\hline $\begin{array}{l}4^{\circ} \text { microciclo } \\
\text { mayo }\end{array}$ & $\begin{array}{l}\text { Baja capacidad de } \\
\text { acción política del } \\
\text { Gobierno; déficit } \\
\text { de articulación y } \\
\text { discurso. Pérdida de } \\
\text { iniciativa. }\end{array}$ & $\begin{array}{c}\text { Desborde de la } \\
\text { cuarentena ( } 40 \%) \text {. } \\
\text { Violencia familiar; } \\
\text { masivo contagio en } \\
\text { la PNP. }\end{array}$ & $\begin{array}{c}\text { Baja capacidad } \\
\text { ejecutiva; se } \\
\text { agravan las crisis } \\
\text { humanitarias. Bono } \\
\text { rural. }\end{array}$ & $\begin{array}{l}\text { Alimentos } \\
\text { disponibles; } \\
\text { prestación regular de } \\
\text { servicios. }\end{array}$ & $\begin{array}{c}\text { En disputa. } \\
\text { Poderes sin } \\
\text { consenso. }\end{array}$ \\
\hline $\begin{array}{l}\text { Ciclo largo } \\
\text { Junio-octubre }\end{array}$ & $\begin{array}{l}\text { Muy escasa capacidad } \\
\text { de acción del } \\
\text { Gobierno; pérdida de } \\
\text { iniciativa; aumento } \\
\text { de confrontación } \\
\text { Ejecutivo-Congreso }\end{array}$ & $\begin{array}{c}\text { Fin de la cuarentena, } \\
\text { reapertura de la } \\
\text { economía. }\end{array}$ & $\begin{array}{l}\text { Primer colapso de } \\
\text { servicios de salud. } \\
\text { Crisis del oxígeno. } \\
\text { Intervención en } \\
\text { regiones. Bono } \\
\text { Familiar Universal. }\end{array}$ & $\begin{array}{c}\text { Alimentos } \\
\text { disponibles; } \\
\text { prestación regular de } \\
\text { servicios. }\end{array}$ & $\begin{array}{l}\text { Sin agenda. } \\
\text { Debilitamiento } \\
\text { de la presidencia. } \\
\text { Tres gabinetes. } \\
\text { Preparación de la } \\
\text { vacancia. }\end{array}$ \\
\hline
\end{tabular}

Fuente y elaboración propias.

\section{Los microciclos posteriores a noviembre}

La destitución del presidente Vizcarra el 9 de noviembre de 2020 instala una nueva inestabilidad; altera el ciclo largo de normalización de la gran depresión y condensa en lo político e institucional todos los desafíos de esta etapa. Se produce un giro sustantivo en las relaciones entre el Gobierno y la sociedad; esta le impone al Congreso decisiones contrarias a la destitución de Vizcarra y emplaza a Sagasti en el poder, más precario que el primero, y rápidamente acosado por la segunda ola. Sagasti es quizás el único presidente del mundo nombrado abrumadoramente por sus enemigos.

i) Microciclo 9-17 de noviembre de 2020 . Es de la ruptura de las reglas de juego democráticas, el golpe destituyente de 
Vizcarra, el rechazo democrático ciudadano, y la restauración y formación de una nueva coalición gobernante (De la Puente, 2020a).

ii) Microciclo 18 de noviembre-31 de diciembre de 2020. Es la formación de una nueva agenda, con base en los sucesos de noviembre, que agrega la demanda de cambios más profundos de nivel constitucional y constituyente a la pandemia, la reactivación de la economía y las elecciones. El Gobierno de Sagasti muestra baja capacidad de acción política, relativa eficacia en el control de la pandemia y pierde el manejo de esa agenda que pasa a la sociedad y a los partidos en campaña electoral.

iii) Microciclo enero 2021. Es de la recuperación de la centralidad de la pandemia por la irrupción de la según ola y la compleja cuestión de la vacuna. El Gobierno muestra una baja eficacia en la respuesta a la segunda ola y se registra un segundo colapso del sistema de salud. El gobierno opera a la defensiva, con eficacia en la agenda de la vacuna y desatiende los reclamos de bonos (que luego concede) y otras ayudas para compensar la cuarentena. La agenda es plural, y en lo que concierne a la pandemia está en disputa.

\section{EL FRACASO PERUANO}

\section{Las tesis sobre el fracaso.}

El fracaso peruano frente a la pandemia es un lugar común poco explicado o dado por sentado. La variedad de tesis que lo explican, en la mayoría de casos sustentan como razón principal el fatalismo, las debilidades del Estado o en la responsabilidad de la sociedad. Entre esa variedad, podríamos citar las siguientes:

i) La tesis determinista, que señala como punto de partida que, a excepción de un puñado de países, el virus ocasiona graves afectaciones humanas y materiales inevitables por el desconocimiento del virus y la rapidez de su propagación, de modo que el fracaso del mundo es una agregación de fracasos nacionales por razones fuera de control. Esta tesis argumenta que tanto en países con fuertes sistemas de salud o estados de bienestar, y en aquellos que carecen de un sistema de salud extendido y de gran cobertura y calidad, los estragos de la pandemia son similares.

ii) La tesis estructural, que explica el fracaso en el abandono de la salud como prioridad social y objeto de financiamiento. Fue la tesis más extendida en el Perú a inicios de la pandemia, y adquirió un carácter oficial desde los pronunciamientos del más alto nivel del Gobierno $^{10}$ y en los otros poderes públicos y la academia. La tesis del abandono puede tener matices, desde aquellas que sostienen que en poco tiempo es difícil revertir esta situación o las que señalan que el modelo neoliberal, aún debilitado, impide ahora mismo la adopción de una respuesta distinta con resultados distintos.

iii) La tesis comunitaria, que explica el fracaso por la indisciplina de la sociedad u otras razones antropológicas relacionadas a la informalidad, resistencia y resiliencia de los peruanos, fenómenos que conducen al acatamiento incompleto de las restricciones o a la inobservancia de las medidas. Esta tesis también presenta matices, entre las que acentúan una razón moral egoísta o adversa al contrato social; las que sostienen la falta de cohesión social, vulnerabilidad de los más pobres que sacrifican la salud por su economía familiar y personal; y las que aluden como primera razón a las debilidades de orden público, es decir, del cumplimiento de las medidas de emergencia por la ineficiencia de las FFAA, PNP, municipios y gobiernos regionales. La variante moralista de esta tesis fue muy extendida en la sociedad durante el Gobierno de Vizcarra y lo benefició en la medida que redujo su responsabilidad en la gran depresión y fortaleció su aprobación.

iv) La tesis de política pública, que explica el fracaso principalmente por los errores del gobierno, primero de Vizcarra y luego de Sagasti. No desconoce los factores fuera de control y los elementos estructurales, aunque coloca el énfasis en la falta de liderazgo presidencial o el mal uso de este, los errores del equipo de gobierno y la elección de políticas de respuesta para la mitigación (compra de equipos, trazado de contactos, reclutamiento del recurso

10 https://www.gob.pe/institucion/presidencia/ noticias/289929-presidente-vizcarra-que-esta-pandemiahistorica-nos-deje-como-leccion-aprendida-que-la-saludes-fundamental-para-el-desarrollo 
humano, entre otros), la organización de la atención hospitalaria, la gestión de las medidas de emergencia y compensación, entre otros. En esta tesis se encuentran también matices, el que alude a la incapacidad política personal de Vizcarra tanto líder de gobierno relacionadas con sus decisiones antes de la pandemia; y los que aluden a los errores en la elección de la respuesta.

Las tesis señaladas explican la naturaleza del fracaso, aunque las tres primeras absolutizan esa explicación restándole el carácter específico a un hecho al mismo tiempo global y nacional. En una perspectiva de ponderación, cada país ha experimentados procesos propios relacionados con los hechos externos; sin embargo, para formar un resultado ha sido fundamental la capacidad, calidad y oportunidad de las decisiones que cada país adoptó, y en cada país los desempeños específicos. En el Perú, por ejemplo, el desempeño del MINSA y de ESSALUD fue muy distinto, en beneficio del segundo.

Sostenemos que, en el caso peruano, la interacción de las explicaciones es decisiva y la consideración de las variables, su evolución en el tiempo, el desempeño de los actores y la complejidad de la agenda pública, juegan un papel muy determinante.

En el período estudiado esta tesis fue minoritaria. En octubre, pocos días antes de la destitución de Vizcarra, la encuesta del IEP de ese mes, revelaba que el porcentaje de quienes responsabilizaban a los ciudadanos de que la pandemia no estuviese controlada era del
$70 \%$, quienes responsabilizaban al gobierno apenas sumaban $15 \%$, en tanto que quienes señalan que se debía a los problemas de salud y economía que no se pueden resolver en pocos meses alcanzaban el 14\%.

\section{El desempeño singular}

La pandemia se desenvuelve en el Perú sobre una realidad especialmente propia, compleja y distinta a la de otros países de la región, y este punto reside la insuficiencia de un análisis estricamente sanitario. El impacto desigual de la pandemia complejiza las correlaciones entre la salud, economía y política.

La pandemia alteró y suministró nuevos fenómenos y significados al escenario que se encontraba en transición luego de la disolución del Congreso el 30 de setiembre de 2019 y debido a la ralentización del crecimiento económico. El Perú había sorteado en los últimos años el efecto combinado de crisis política más crisis económica que afectó a sus vecinos limítrofes, e hizo gala de una ponderación colectiva en los eventos del año 2019 a pesar de la trascendental tensión que significó la disolución del Congreso y el proceso contra la corrupción, a diferencia de los procesos violentos en Chile, Ecuador, Bolivia y Colombia. La reducción del crecimiento no alimentó la crisis institucional y es probable que incidiera en ello la receta de la gobernabilidad del período posterior a Fujimori, las "cuerdas separadas" entre economía y política, la debilidad de los actores políticos y la sociedad civil y las salidas, como se puede apreciar en el siguiente cuadro comparativo.

\section{Cuadro 2. Detonantes, actores, demandas y expectativas en las protestas en la subregión andina 2019}

\begin{tabular}{|l|l|l|l|l|}
\hline \multicolumn{1}{|c|}{ País } & Detonante/Gobierno & \multicolumn{1}{c|}{ Demandas agregadas } & Actores demandantes & \multicolumn{1}{c|}{ Mecanismo de salida } \\
\hline Ecuador & $\begin{array}{l}\text { Medidas económicas/ } \\
\text { Liberal }\end{array}$ & Desigualdad, discriminación & $\begin{array}{l}\text { Índigenas, CONAIE, } \\
\text { Frentes }\end{array}$ & Mesa de diálogo \\
\hline Chile & $\begin{array}{l}\text { Medidas económicas/ } \\
\text { Neoliberal }\end{array}$ & $\begin{array}{l}\text { Desigualdad, corrupción, } \\
\text { servicios públicos }\end{array}$ & Sociedad civil & Asamblea Constituyente \\
\hline Bolivia & Reeleción/Izquierda & Reelección presidencial & Comités cívicos & Nuevas elecciones generales \\
\hline Perú & Corrupción/Liberal & Corrupción reforma política & $\begin{array}{l}\text { Gobierno, medios, } \\
\text { movimientos sociales }\end{array}$ & $\begin{array}{l}\text { Nuevas elecciones } \\
\text { parlamentarias }\end{array}$ \\
\hline Colombia & $\begin{array}{l}\text { Seguridad, medidas } \\
\text { económicas/Neoliberal }\end{array}$ & $\begin{array}{l}\text { Acuerdos de paz, impuestos, } \\
\text { servicios públicos }\end{array}$ & Movimientos sociales & Mesas de diálogo \\
\hline
\end{tabular}

Fuente y elaboración propias. 


\section{Las preguntas del fracaso}

En consideración a lo señalado, se tiene dos preguntas cruciales para una inicial determinación de las causas del fracaso peruano frente al Covid-19:

i) ¿Por qué no fue posible establecer un modelo peruano para enfrentar a la pandemia en lo sanitario y sus efectos en otros ámbitos, especialmente los económicos y sociales, $\mathrm{y}$ qué factores desencadenaron el cambio en la tendencia, de una inicial y aparente respuesta supuestamente eficaz hacia el fracaso?

ii) ¿En qué medida la crisis política que "encontró" la pandemia fue decisiva para convertir la crisis sanitaria en una gran depresión con varias crisis "grandes" y "pequeñas", es decir, cuáles fueron los roles de las instituciones, liderazgos e interacciones, de modo que no se cumplieran las predicciones sobre cambio e innovación?

\section{AGENDAS Y ACTORES DE LA GRAN DEPRESIÓN}

\section{Las primeras agendas}

El Gobierno tuvo una respuesta inicial considerada exitosa frente a la pandemia, reconocida dentro y fuera del país, y es probable que ese reconocimiento pudiese haber implicado un exceso de confianza en el liderazgo presidencial interno. Vizcarra y su Gobierno construyeron en marzo de 2020 una narrativa unitaria frente a la pandemia a partir de una primera agenda de un punto único, la salud; comunicaron acertadamente, controlaron el desorden inicial en el sector Salud con la designación del ministro Zamora, movilizaron el acatamiento de la cuarentena con mucho esfuerzo, aprobaron el primer Bono "Quédate en Casa" y adoptaron medidas de apoyo a las empresas (De la Puente, 2020b). De ello resultó la presunción de que el Gobierno tenía una política frente a la pandemia ${ }^{11}$. Los balances positivos en marzo 2020, a pocos días de declarada la cuarentena, en respuesta a la incertidumbre hacían énfasis en que el presidente y el Gobierno reaccionaron con

11 Una de las notas de reconocimiento más resonante fue de la BBC: https://www.bbc.com/mundo/noticias-americalatina-52104166 firmeza y en la dirección correcta, con "autonomía para privilegiar el interés público sobre el privado", lo que evidenciaba que, como Estado, habíamos mejorado en los últimos años (Tanaka, 2020).

Esta narrativa se diluyó gradualmente y pasó a sostenerse en la palabra presidencial altamente cotizada en lo político, pero cedió frente a los problemas de gestión que rápidamente fueron adjudicadas a las limitaciones estructurales del sistema sanitario. Disminuyó la capacidad del Gobierno para ejecutar las medidas que expedía y hubo confusión en aspectos cruciales de la pandemia y la crisis económica que irrumpía: las pruebas moleculares y serológicas, el retiro de fondos de las AFP, los beneficiarios del Programa Reactiva Perú, la suspensión perfecta laboral y la situación del agro. Emergieron al mismo tiempo nuevos discursos contra la pandemia desde abajo, en tanto que la narrativa pública -las voces de la sociedad- se independizó desde abril de 2020. Se formó una segunda y nueva agenda de la pandemia; esta era dual o mixta, con la salud y los ingresos como sus principales elementos, y se hizo patente el desborde del aislamiento y la aparición de dilemas clásicos "pobres/ ricos, arriba/abajo empresarios/trabajadores, público/privado, formales/informales y mano blanda/mano dura" (De la Puente, 2020b).

La narrativa oficial sobrevivió un tiempo sin oposición organizada. El Gobierno comunicó menos. La verbalización de la pandemia como una guerra puso por delante a los ejércitos, debilitó el sentido de la unidad nacional, intentó suprimir la deliberación pública y desmovilizó al país (Idem). De modo inevitable, la agenda se reordenó y se amplió con la profundización de la crisis económica.

En la tercera agenda, que pasó de dual a plural, instalada en mayo de 2020, el 15 de marzo, cuando se declaró la cuarentena, era lejano y la promesa que entonces significaba, había concluido. La pandemia era el punto básico, pero no el único; contaban el hambre, desempleo, alquileres, bonos, créditos, violencia familiar, personas privadas de su libertad, las crisis humanitarias que se formaban en regiones, el cierre de negocios pequeños, la actividad educativa escolar y universitaria, entre otros. El Perú ya venía de una etapa de grandes demandas que, no obstante, eran respondidas de modo limitado por la política. 
En las semanas previas al cambio de gabinete, en julio de 2020, la agenda se tornó confusa y acaso difusa. El país se encontraba a la espera de un nuevo discurso general sobre la pandemia, aunque la única perspectiva era la reactivación de la economía, que acabó siendo la única certidumbre pública, y aún ella carecía de un horizonte identificado. Un nuevo gabinete -el de Cateriano- coincidió con el inicio de la fase 3 de la reactivación de la economía (se inició el 1 de julio ${ }^{12}$ ) y con ella la economía empezó a funcionar al $90 \%$, y la designación del gabinete Martos coincidió con el inicio de la caída diaria de los contagios. (Gráfico 1).

\section{Gráfico 1. Reporte diario de casos y fallecidos. Diario La República}

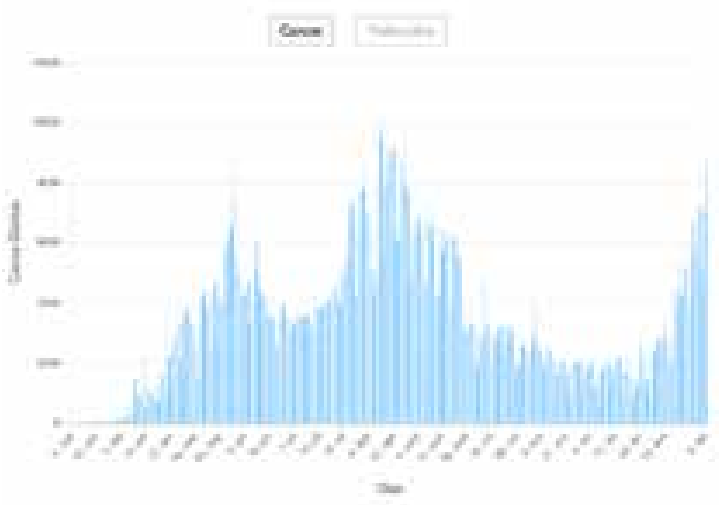

Fuente: Diario La República. Reportes diarios de casos confirmados de muertes por coronaviris en Perú. ${ }^{13}$

El país anduvo sin agenda para la gran depresión los meses de setiembre y octubre, una etapa dominada por la crisis política, es decir, las acusaciones contra Vizcarra que desembocaron en la primera moción de vacancia (setiembre de 2020). Se vivía "un momento de nadie" sin orientación sostenido en el esfuerzo de la primera línea contra la pandemia. Del gabinete presidido por el general retirado Walter Martos que inició sus funciones en agosto se esperaba un programa básico

12 En mayo de 2020, el gobierno aprobó mediante el D.S $\mathrm{N}^{\circ}$ 080-2020-PCM la reanudación de las actividades económicas en cuatro fases. La Fase 1 se inició el 2 de mayo, la Fase 2 el 4 de junio, la Fase 3 el 1 de julio y la Fase 4 el 1 de octubre, con un retraso de dos meses. https:// busquedas.elperuano.pe/normaslegales/decreto-supremoque-aprueba-la-reanudacion-de-actividades-ec-decretosupremo-n-080-2020-pcm-1865987-1/

13 https: / / data.larepublica.pe/envivo/1552578-casosconfirmados-muertes-coronavirus-peru contra la pandemia. La economía se había independizado de la pandemia y progresaba la sensación de que la reactivación favorece a los de siempre (De la Puente, 2020c).

\section{Aprobación escindida y resiliencia}

Hasta su destitución, Vizcarra gozó de una alta aprobación. La encuesta del Instituto de Estudios Peruanos (IEP) de octubre de 2020 registró $60 \%$ de aprobación presidencial, aunque la aprobación de su gobierno era de 20 puntos menos (40\%). Cuando fue predominante la agenda única contra la pandemia, o la agenda dual de la pandemia y el empleo/ingresos, e incluso cuando esta se hizo más plural, su aprobación se mantuvo por encima del $50 \%$. El presidente obtuvo hasta $92 \%$ de aprobación en los momentos iniciales de la pandemia y el Congreso inicialmente escaló hasta el $47 \%$. No se podría decir que el Gobierno tenía las manos atadas para impulsar políticas eficaces contra la pandemia y la crisis económica.

El aumento de contagios por encima de los 10 mil casos inició la caída de las aprobaciones, a excepción inicialmente del Congreso que mantuvo cierta expectativa luego de la aprobación de la ley del retiro del $25 \%$ de aportes a las AFP; esta aprobación escaló hasta el $49 \%$ el mes de junio, para luego emparejarse con la disminución de las aprobaciones de los poderes que se hacía más insistente en las siguientes mediciones. A pesar de otros movimientos legislativos contrarios al Ejecutivo, el Congreso no pudo volver a generar expectativas en la opinión pública.

La reactivación de la economía y la reapertura del Estado no se reflejó en el aumento de la aprobación de los poderes públicos, de modo que los aspectos positivos de las políticas públicas se neutralizaron con los deficitarios. Se apreció así una relación entre el aumento de los casos, las muertes y las crisis humanitarias con la aprobación de los poderes públicos.

La aprobación y desaprobación del gobierno, especialmente hasta octubre, de acuerdo a la medición del IEP de ese mes, presentaba diferencias. El presidente mantenía una alta aprobación de $60 \%$ a pesar de haber caído varios puntos porcentuales (entre abril y octubre perdió 32 puntos de aprobación), al mismo tiempo que los sondeos exhibían un amplio nivel de tolerancia social respecto al desempeño del Gobierno sobre la pandemia, 
mereciendo los calificativos de entre bueno y regular, que en la encuesta de IEP sumaban $72 \%$. Ese mes, solo el $10 \%$ creía que el Vizcarra y su equipo de Gobierno manejaba mal la crisis del Covid-19. No se requiere demasiada imaginación para concluir que la falta de revisión de las políticas públicas para encarar la pandemia se relacionaba con alguna intensidad con la falta de deliberación y de crítica social.

En esa etapa, la población tenía preocupaciones parejas sobre la situación económica del país y la progresión de los contagios del Covid-19. La gravedad de la situación y la alta aprobación presidencial proyectó en el caso de Vizcarra que la dinámica aprobación/desaprobación era escindida, porque al mismo tiempo la opinión publica reconocía los esfuerzos del gobierno contra la pandemia y era relativamente tolerante respecto a sus fracasos, de modo que carecía de un juicio absolutamente negativo y crítico. La aprobación escindida reflejó tanto una comprensión exagerada de los límites autoimpuestos del Gobierno por parte de la opinión pública -impulsada por el discurso oficial- como la resiliencia de los peruanos que de modo creciente desconfiaban de las posibilidades del Estado para atender sus demandas. Así, la aprobación escindida de Vizcarra fue también la expresión de que los peruanos bailaban "con su pañuelo".

Por lo tanto, esa aprobación era más que la aprobación tradicional; su sentido era también "hacia adentro". Además de aprobación, expresaba esperanza, demanda, expectativa y reclamo, inclusive, en el contexto de crisis y de disolución o bloqueo de liderazgos alternativos, aunque de un modo pasivo. Ese modelo de aprobación parece no tener vigencia con el presidente Sagasti, al que el sondeo de IEP de enero le otorgó solo el $20 \%$ de aprobación, es decir, una aprobación desnuda, sin esperanza y sin expectativa.

Hasta la destitución de Vizcarra, se redujo la participación de la sociedad en los asuntos públicos. En este punto se experimentó una forma de desmovilización y escasa deliberación pública, la misma que era intensa en la elite y en los medios. Aun así, debe tenerse en cuenta el aumento de los conflictos sociales desde mayo, la falta de solución de los mismos y la irrupción de conflictos generados por la deficiente gestión de la pandemia.
La dinámica entre movilización $\mathrm{y}$ desmovilización en esa etapa fue compleja. Por una parte, se activaron y reactivaron conflictos sociales e irrumpieron otros nuevos por razones de la pandemia -como las demandas a que las empresas mineras entreguen bonos a la población de su radio de acción - aunque los conflictos no se agregaron políticamente para producir una crisis sustantiva. Luego, en varios momentos las tensiones entre los poderes no se refirieron a la crisis económica (salvo a los aportes a las AFP y ONP) o al manejo de la pandemia, sino a la reforma política y a las elecciones del próximo año, una prioridad que la opinión pública no seguía con atención. Los proyectos de ley sobre el Bono Universal presentado por el Frente Amplio ${ }^{14}$ y de la entrega de un bono a los trabajadores contagiados de Covid-19 presentado por Fuerza Popular ${ }^{15}$, no tenían en enero del 2021 dictamen alguno de las comisiones de Presupuesto e Inclusión del Congreso a las que fueron derivados, respectivamente.

A pesar de ello, los peruanos eran más ponderados o moderadamente optimistas; eran conscientes de su situación, del riesgo de contagio y de la falta de progreso familiar, pero el 59\% señalaba que la situación económica era regular, el $35 \%$ que era entre mala y muy mala, y el $7 \%$ que era entre buena y muy buena, según la encuesta de IEP de octubre, una correlación entre el realismo y la resiliencia.

\section{LA RESPUESTA PERUANA}

El Gobierno encaró la pandemia desde tres ámbitos: 1) respuestas en salud pública; 2) respuestas políticas e institucionales; y 3) respuestas en el ámbito económico, de subsidio y apoyo.

\section{La respuesta en salud pública}

El Gobierno expidió un grupo de medidas de mitigación y supresión que aspiraba a ser un modelo. Pareció lograr ese objetivo en las primeras semanas de la emergencia. Adoptó -en realidad adecuó- la legislación existente para ordenar una Estado de Emergencia con

14 Presentado en junio de 2020. https://leyes.congreso.gob. pe/Documentos / 2016_2021/Proyectos_de_Ley_y_de_ Resoluciones_Legislativas/PL05435-20200604.pdf

15 Presentado por junio de 2020. https://leyes.congreso. gob.pe/Documentos/2016_2021/Proyectos_de_Ley_y_de_ Resoluciones_Legislativas/PL05553_20200617.pdf 
cuarentena, articulando creadoramente una disposición constitucional (artículo 137) y otra de la Ley General de Salud (artículo 82). La emergencia peruana fue considerada oportuna y severa: cierre de fronteras, aislamiento obligatorio, inmovilización total de la población en horario nocturno y un día a la semana, distanciamiento social, restricción general de la economía, suspensión del servicio educativo y cierre de las actividades no esenciales del Estado.

El Gobierno dispuso otras medidas luego del cambio de ministro de Salud el 20 de marzo que permitió ordenar las prioridades: 1) adquisición extraordinaria de equipo del área de emergencia, equipo de protección para el personal de salud, medicinas y pruebas de descarte; 2) reforzamiento de la infraestructura física de los hospitales, contratación de personal y suministro de bonos extraordinarios; 3) unificación en el terreno de las redes y sistemas de salud mediante la creación del Comando Covid; y 4) aprobación de decenas de directivas sanitarias a cargo del MINSA sobre la gestión hospitalaria, detección del Covid, atención a los pacientes, suministro de medicinas, manejo de cadáveres, entre otros.

\section{La respuesta politica e institucional}

La pandemia encontró al país de salida del proceso crítico de los años 2016-2019 y de ingreso a otro en la dirección de las elecciones del año 2021. El empeño de las instituciones se orientaba a establecer un curso de transición hacia la última etapa del Gobierno y del Congreso elegido el pasado 26 de enero. La pandemia se situó sobre una realidad en movimiento con actores que tomaban posiciones para cumplir su papel en los meses siguientes.

El Estado de Emergencia de marzo de 2020 transformó a las instituciones, elevó el papel político del Gobierno, convirtió al Congreso en obligado aliado de este por algunas semanas e inmovilizó inicialmente a organismos constitucionalmente autónomos a excepción de la Defensoría del Pueblo, el BCR, la Superintendencia de Banca y Seguros y la Contraloría General de la República. Afectó el proceso anticorrupción que impulsa el Ministerio Público, aunque la actividad de la fiscalía fue requerida rápidamente para los casos de corrupción que se registraron en medio de la cuarentena.
El Gobierno sustentó su actividad en el liderazgo del presidente Vizcarra, en su vocería casi única y en la adopción de normas de emergencia. El temor colectivo, la rápida progresión de los contagios y las primeras medidas audaces generaron un momento de unidad nacional caracterizado por la adhesión a una agenda única y la postergación de los quehaceres y objetivos específicos. La forma de exponer esta política fue a través de conferencias de prensa diarias como el principal vehículo de comunicación gubernamental. Este formato de relación con la sociedad elevó el papel del presidente de la República, muy útil en esas circunstancias, pero no fue acompañado de otras formas de comunicación más sostenibles, especialmente la comunicación del riesgo, campañas educativas y otras vocerías permanentes, como lo aconsejaban varios especialistas. Salvo los ministros de Salud, Economía y el presidente del Consejo de Ministros, durante semanas el país se atuvo a una relación plebiscitaria planteada desde el poder.

Esta escena predominante permitió, no obstante, la puesta en valor del llamado Consejo de Estado en un aprendizaje práctico que será de una utilidad crucial en los próximos años para la gobernanza y la estabilidad. La dinámica de este espacio es creciente y enriquecedora $\mathrm{y}$ ha funcionado como mecanismo de diálogo público trasversal algunas veces en interés del Ejecutivo y otras de los organismos constitucionalmente autónomos. El presidente lo convocó el 8 y 15 de abril de 2020, la primera de las fechas para promover el respaldo a la segunda ampliación de la cuarentena; el 8 de mayo con el mismo propósito, y otras veces de modo no público. El 9 de julio fue convocado para resolver la tensión con el Congreso luego de las sorpresivas modificaciones a la Constitución llevada a cabo el 5 de julio. Sagasti convocó al Consejo de Estado en varias oportunidades.

Como parte de la respuesta a la pandemia, el Gobierno solicitó el 26 de marzo de 2020 al Congreso facultades delegadas por 60 días en las siguientes áreas: 1) salud; 2) política fiscal y tributaria; 3) promoción de la inversión pública; 4) seguridad ciudadana y orden interno; 5) trabajo y promoción del empleo; 6) educación; 7) prevención y protección a la población en situación vulnerable; 8) servicios públicos y bienes esenciales; y 9) sectores 
productivos y extractivos, micro, pequeñas, medianas y grandes empresas. El Congreso lo aprobó el mismo día del pedido por un plazo de 45 días.

La producción legislativa no fue abundante. Se emitieron 61 decretos legislativos, una cantidad menor que los 112 decretos legislativos que expidió el Gobierno de Kuczynski el 2017 para reactivar la economía y modernizar el Estado, o los que se expidieron durante el premierato de César Villanueva.

Los decretos permitieron dos propósitos a ser rescatados como contenido explícito de la cooperación de las instituciones: 1) culminar la creación normativa de la emergencia y su excepcionalidad; y 2) constituir el núcleo normativo de la reactivación de la economía. El control político de esta legislación delegada, que el Congreso no ha completado, reafirmará la participación del Parlamento en la conducción de la primera parte de esta etapa.

Confirman la importancia de esta producción normativa algunos de los siguientes decretos legislativos: 1) el que crea el Programa Reactiva Perú para asegurar la continuidad en la cadena de pagos y garantizar el financiamiento de la reposición de los fondos de capital de trabajo de empresas a través de un mecanismo que otorgue la garantía del Gobierno a los créditos en moneda nacional inicialmente por 30 mil millones de soles; 2) que crea el Procedimiento Acelerado de Refinanciación Concursal (PARC) para que las micro, pequeñas, medianas y grandes empresas, celebren con sus acreedores el Plan de Refinanciación Empresarial; 3) que aprueba medidas para reactivar la actividad turística a través del Programa Turismo Emprende; 4) que permite el fraccionamiento de hasta 36 meses de las deudas tributarias administradas por la SUNAT; 5) que dispone el retorno gradual al sector público a sus actividades laborales; 6) que fija el marco normativo que permite a los trabajadores del Estado el trabajo remoto, las modalidades mixtas de prestación del servicio, reducir la jornada laboral, modificar el horario de trabajo, establecer turnos de asistencia, proporcionar medios de transporte para el traslado de los servidores civiles al centro de labores y de vuelta hacia un punto cercano a sus domicilios, y proporcionar los equipos de protección personal, entre otros; 7) que impulsa la telesalud, telemedicina, teleconsulta, teleinterconsulta, teleorientación y telemonitoreo; 8) que garantiza la protección de los derechos de los trabajadores en el marco de la emergencia; 9) que permite prácticas pre profesionales virtuales; 10) que establece acciones para la protección de los pueblos indígenas $\mathrm{u}$ originarios en el marco de la emergencia; 11) que fortalece la prevención, atención y protección de la persona adulta mayor durante la emergencia; y 12) que simplifica el procedimiento para que las mujeres en riesgo de ser agredidas o asesinadas cuenten con medidas de protección durante la emergencia, entre otros.

No obstante, el Gobierno se sustentó apenas en los gobiernos locales fue mínima. No puede afirmarse que en la emergencia se aprovechó satisfactoriamente el marco legal de los gobiernos locales como organismos ubicados de modo más cercano al ciudadano. Tempranamente, el 26 de marzo de 2020, se dispuso la entrega por los municipios de canastas de alimentos por 213 millones de soles y luego se dispuso que participen en la entrega de alimentos bajo el liderazgo de INDECI y la Presidencia del Consejo de Ministros. En el primer caso, la Contraloría realizó una supervisión en más de 1,300 municipalidades y documentó irregularidades en el proceso de focalización, la compra de los alimentos, la entrega por los proveedores, el almacenamiento y la rendición de cuentas. El 17 de mayo de 2020 reportó que el $15 \%$ de las municipalidades a nivel nacional no había transparentado toda la información respecto a la compra y entrega de las canastas, y el 10 de junio, según el Monitor de Control de Transparencia Covid-19 de esa institución, se contaban 107 mil canastas que no habían sido adquiridas, de las cuales 49 mil corrían el riesgo de no llegar a poder de los beneficiarios.

Es importante que se precise la capacidad de los gobiernos locales para asumir funciones en la emergencia. Es cierto que la calidad e idoneidad de las autoridades locales son distintas; no obstante, es trasversal la pérdida de capacidades locales en la gestión social y la defensa de derechos especialmente sensibles en las municipalidades con mayor concentración de población, y la falta de veeduría y participación de la comunidad. A esta deficiencia concurrieron los problemas en la focalización de hogares vulnerables, la falta de protocolos obligatorios (las canastas 
variaron en precio y volumen), la corrupción, y la inexplicable resistencia del Gobierno a innovar la entrega de alimentos a través de tarjetas y transferencias dinerarias de gran eficacia y transparencia.

El Gobierno recurrió a los municipios en lo estrictamente necesario, y en otros casos evitó sobrepasar sus funciones con medidas de recentralización luego de que se hiciesen concluyentes los resultados adversos en ámbitos sensibles, especialmente en la fiscalización, como en el caso de las aglomeraciones en los mercados y centros de abasto.

En el contexto de esa interacción mínima fueron destacables los decretos de urgencia que transfirieron partidas con cargo a los recursos de la Reserva de Contingencia del Ministerio de Economía y Finanzas para el financiamiento del gasto operativo esencial en respuesta a la menor recaudación de ingresos por la emergencia; la entrega de 17 millones de soles para financiar la adquisición de kits de limpieza, desinfección y seguridad para comedores populares; y la entrega de 6 millones de soles a los municipios para financiar la elaboración de fichas de actividades de intervención inmediata, para reactivar la inversión pública.

La interacción con las regiones fue de un nivel medio; sobresalió en ella la ayuda de emergencia para la mitigación del colapso de las redes de salud en varias regiones, como Piura, Tumbes, Lambayeque, Loreto, Arequipa y Huánuco, entre los más dramáticos. Esta interacción se realizó luego de constatarse la baja calidad de la infraestructura y prestaciones como resultado de una depresión de largo plazo de los servicios de salud, concurrente con una gestión deficiente de los contagios. En esta realidad se hizo patente la vigencia de las tesis de políticas públicas: regiones con igual o parecido déficit en salud tuvieron, no obstante, desempeños y resultados desiguales.

En el análisis de la interacción Gobierno Central/Regiones debe considerarse el factor desencadenante del aumento de casos, estableciéndose como regla general una gradual "ronda" de crisis caracterizada por el aumento de casos como determinantes. Esta "ronda" se inició en el norte del país, pasó a la Amazonía, luego al sur y posteriormente al centro.
Puede identificarse algunos gobiernos regionales con un mejor desempeño que otros en la gestión de la pandemia. Un caso de mejor desempeño es el Cajamarca, y en el extremo contrario se cuenta Loreto, Arequipa y Huánuco.

En el período estudiado, el Gobierno sostuvo en las regiones parte de la gestión de la crisis humanitaria del desplazamiento interno; varios decretos de urgencia transfirieron a las regiones recursos para la contratación de servicios, alojamiento temporal y alimentación de los desplazados; y la adquisición de insumos y equipo médico, contratación de personal y formación de equipos de respuesta rápida para lo que se creó un presupuesto especial de cada región, el Presupuesto Covid, asignado a través de tres decretos de urgencia (DU 025, DU 026 y DU 039) y una modificación del presupuesto de apertura.

La evolución de este presupuesto marca las capacidades regionales en la crisis: 7 regiones ejecutaron su presupuesto por encima del $50 \%$ (Arequipa, Tumbes, Lambayeque, La Libertad, Callao, Lima y Ucayali), otras 7 entre el $40 \%$ y 50\% (Cajamarca, Ancash, Tacna, Piura, Loreto, Ica y Puno), y otras 10 por debajo del 35\% (Huancavelica, San Martín, Apurímac, Junín, Huánuco, Cusco, Ayacucho, Pasco, Moquegua y Amazonas).

\section{Respuesta en el ámbito económico, subsidio y apoyo}

Desde que empezó la emergencia sanitaria hasta el 14 de julio de 2020 se asignaron 90 mil millones soles para la estrategia sanitaria, soporte a las familias y empresas, continuidad de la educación y apoyo a los gobiernos regionales y locales, y la reactivación económica.

Sobre la reactivación, el gobierno puso en marcha un plan que, de acuerdo al BCR, involucra casi 15 por ciento del PBI si se incluye las medidas sanitarias, tributarias, apoyo a las empresas, transferencias directas, y financiamiento de sectores públicos críticos por la falta de recursos propios. En el soporte de la economía se invirtió el $19.1 \%$ del PBI del año 2019 desagregado en cuatro sectores: Gobierno (3.3\%), BCR, (8.7\%), empresas $(1.8 \%)$ y hogares $(5.3 \%)$. 
Las medidas perseguían aliviar las cargas a las familias y empresas y evitar la suspensión de la cadena de pagos y servicios. Sobre las empresas, se decidió la creación del Programa Reactiva Perú que garantizó los créditos colocados por las empresas del sistema financiero inicialmente con 30 mil millones en garantías que luego se amplió a 60 mil millones, equivalentes al $8 \%$ del PBI. El programa fue objeto de crítica, tanto por la reducción de la cobertura y el tiempo de apoyo a las empresas, como por que varios de los beneficiarios recurrieron a la suspensión perfecta de sus trabajadores, una medida extrema en el ámbito laboral. Luego se amplió el límite de los créditos, y se flexibilizaron las condiciones para favorecer el acceso de las microempresas para la segunda etapa del programa, y se dispuso que los créditos cumplan con el requisito de idoneidad del contratante -como identificación de las empresas investigadas por corrupciónpara lo cual se instaló el Sistema de Atención de Denuncias en COFIDE luego de que el portal Ojo Público revelara que 14 compañías bajo sospecha de defraudación tributaria, lavado de activos y corrupción, fueron objeto de crédito. ${ }^{16}$

El Gobierno también autorizó el retiro de las cuentas de ahorro de Compensación por Tiempo de Servicios (CTS) y las Cuentas de Capitalización Individual de las AFP, que los trabajadores bajo suspensión perfecta de labores retiren mensualmente el monto equivalente a su remuneración mensual, y tuvo que aceptar la decisión del Congreso convertida en ley por el mecanismo de insistencia de permitir el retiro de hasta del $25 \%$ de los ahorros en las AFP.

El gobierno anunció en distintos momentos del período bajo estudio la entrega de nueve tipos de ayuda a la población vulnerable a través de transferencias directas, indirectas y alimentos: 1) el subsidio de un porcentaje de salario menores a 1,500 soles en las empresas privadas; 2) el primer bono de los 380 soles a las familias pobres, Yo me quedo en casa, que tuvo una segunda entrega; 3 ) las canastas de víveres por los municipios, INDECI y las FFAA; 4) un segundo bono a trabajadores independientes por 760 soles; 5) un tercer bono para el agro, el Bono Agrario, de 760 soles; 6) el Bono Familiar Universal por el mismo

16 https: / / ojo-publico.com/1900/bancos-prestaronempresas-vinculadas-lava-jato-y-panama-papers monto, en el mes de mayo; 7) el mismo bono para nuevos beneficiarios anunciado el 25 de julio con una larga duración en su entrega; 8) el Bono de Electricidad de 160 soles; y 9) el bono de la segunda ola anunciada por el gobierno de Sagasti en enero 2021.

El esquema del Bono Familiar Universal fue el más innovador; siguió el mismo sentido de la reciente universalización de salud, es decir una focalización inversa que se basa en el principio de no centrarse en los que no necesitan de ayuda, sino los que sí lo necesitan y carecen de ingresos formales reconocidos. La norma que lo autorizó planteó las siguientes condiciones a los hogares: 1) que no hayan sido beneficiarios previos de otro bono; 2) que no cuenten con un miembro del hogar en planilla del sector privado o público; y 3) que no cuenten con un miembro del hogar con ingresos por encima de 3 mil soles según la información disponible en el sistema financiero y tributario (BCRP, 2020a).

Los bonos fueron bien recibidos por la población a pesar de que el procedimiento de entrega fue desorganizado. El anuncio de la entrega del primer bono se realizó el 16 de marzo de 2020, y el 22 de ese mes, en seis días, se encontraba en funciones la plataforma de pago para 2.7 millones de familias. El 23 de marzo de 2020 se iniciaron los pagos y en dos semanas el $60 \%$ de los beneficiarios había cobrado el subsidio. Luego, la política de bonos se amplió para más de 700 mil trabajadores independientes, la mayoría informales, cuya plataforma estuvo a punto el 7 de abril. En ese momento, el Perú era el país pionero de las transferencias directas a los sectores vulnerables en América Latina.

Es relevante que la política de las transferencias directas se concretara en pocas semanas. En este punto debe recordarse la resistencia del Estado a subsidios no condicionados puesto de manifiesto durante el Niño de Costero del año 2017, a lo que accedió luego.

Este proceso fue imperfecto, y se concretó a pesar de las trabas de acceso al mercado y el formato de focalización de las familias vulnerables. Carolina Trivelli, ex ministra de Desarrollo e Inclusión Social (MIDIS) consideró en ese momento que si todos estuviéramos conectados a través de alguna cuenta -básica, transaccional o de dinero electrónico- como la que posee todo ciudadano en otros países, 
atada a su documento de identidad, o si todos usáramos sistemas digitales de pago como tarjetas prepago, de débito o nuestros teléfonos estuvieran asociados a nuestras cuentas -como Tunki, Lukita o Yape- o a una billetera electrónica -como BIM- podríamos mantener actividades comerciales sin contacto físico y el pago de los bonos habría sido masivo (Trivelli, 2020).

La intensidad de la política de los bonos se atenuó al punto de comprometer el componente de demanda de la reactivación. La primera crítica provino desde el mismo BCR en cuyo Reporte de Inflación de junio de 2020 se indicaba que la cobertura de 6.2 millones de hogares, si bien era extensa, sufría en la práctica retrasos en la aprobación de los padrones y la entrega de subsidios, lo que podría restarle efectividad a la política si es que la ayuda no se proveía oportunamente y los hogares se veían igualmente obligados a laborar (BCR, 2020b). Por ejemplo, el segundo tramo del Bono Independiente demoró dos semanas en hacerse efectivo desde su anuncio, el Bono Rural inició el pago el 13 de mayo de 2020 (habiendo sido anunciado el 19 de abril), y el Bono Familiar Universal inició operaciones con un padrón incompleto dos semanas después del decreto de urgencia que lo oficializó. Según el MIDIS, al 14 de junio de 2020, alrededor de 5.1 millones de hogares habrían recibido algún bono, dejando casi al $15 \%$ de bonos pendientes de entrega (Idem).

El segundo cuestionamiento se refiere a la frecuencia. Con la extensión de la cobertura del Bono Familiar Universal se tenía en julio de 2020 que 8.5 millones de familias recibirían -si todas hacían efectiva la cobranza- una transferencia de 760 soles que equivale a un mes de los cuatro que hasta ese momento componían la emergencia, es decir, que el Estado entregaba bonos por el importe de un mes. En Chile el bono fue de 320 dólares en los meses de abril y mayo, en pagos mensuales, y de 490 dólares los meses de junio, julio y agosto, en pagos igualmente mensuales. En Argentina, el bono fue de 150 dólares durante tres meses y en Colombia se han entregado bonos adicionales entre 25 dólares a 95 dólares a los beneficiarios de tres programas sociales.

Aun considerando este avance, las transferencias directas no fueron suficientes para la compensación a los más vulnerables y para la reactivación. Es cierto que la provisión de los bonos fue un paso decisivo en la extensión de la protección social a las personas que no necesariamente figuraban en los programas de focalización como pobres o pobres extremos y resumió la tendencia de ampliar la política social en una cobertura mayor a la que brindan la mayoría de los programas vigentes, pero la destrucción del capital social de millones de peruanos fue evidente, de modo que el abandono de este reclamo urgente fue parte del fracaso peruano ante la pandemia, otro aspecto que también pertenece a las eficacia de las políticas públicas.

Los datos previos a la pandemia indicaban que al $20.5 \%$ de pobreza nacional había que agregar el $40 \%$ de peruanos que son "no pobres vulnerables", de acuerdo al estudio de Indice de Desarrollo Humano (IDH) del PNUD publicado el año 2019 (PNUD Perú, 2019). Agregadas las cifras se tendría un universo de $60 \%$ de peruanos que de algún modo requerían de la protección del Estado más aún en una etapa de gran depresión, mediante transferencias directas $\mathrm{u}$ otros mecanismos de alivio como, por ejemplo, la postergación de pagos de impuestos, subsidio del pago de los servicios de luz, agua y teléfono o de la entrega permanente de alimentos.

\section{RAZONES Y TENDENCIAS DEL FRACASO}

\section{Las razones}

Considerando que la pandemia significa un evento mundial extremadamente crítico y que al mismo tiempo presenta un resultado adverso respecto a las primeras previsiones, el uso de la categoría fracaso no es ni arbitraria ni excesiva. Estuvo presente desde el primer momento de la pandemia, tanto como "colapso" para la medicina, "catástrofe" para sociología (Touraine, 2020) o literalmente "fracaso" para la filósofía (Chu-Han, 2020), sentidos comunes que dieron paso a fórmulas de medición de los efectos de las medidas tomadas por cada estado, con lo que se intenta correlacionar el carácter global de la pandemia y las respuestas nacionales y su singularidad.

Las mediciones sobre el mejor o peor desempeño ante la pandemia y las depresiones que ella ocasiona contradice una de las tesis 
radicales que explica de antemano el fracaso, la tesis determinista, en base a indicadores creíbles que operan en las áreas de mitigación y hospitalización de la realidad pandémica, aunque debe reconocerse que no miden otros efectos, entre ellos el económico. Aun así, es obvio que, a menores estragos del virus, las restricciones serán menores luego de un tiempo prudencial.

Es también recurrente la idea del fracaso anunciado como expresión del fracaso obligado de la gobernabilidad neoliberal que forma parte de la tesis estructuralista, y que propugna que la emergencia sanitaria ha evidenciado una serie de contradicciones sistémicas que muestran la fase descendente de la curva civilizatoria moderna capitalista, una fractura total del sistema debido a una serie de contradicciones, cuyo estallido ya fue anunciado y que sin embargo no se lo asumió como realidad efectiva (Sierra, 2020), con lo que poco habría que debatir sobre las respuestas. Varios países, algunos de ellos Ecuador y Chile, donde las condiciones sistémicas del abandono de la salud en cobertura y financiamiento son parecidas a la del Perú, presentaron un mejor desempeño, más aún en el caso de Ecuador, que se recuperó relativamente de los primeros efectos dramáticos en abril y mayo de 2020, y donde se ejecuta un programa neoliberal con marcados tono de los años ochenta.

La tesis de política pública puede explicar mejor el fracaso peruano. Actuando sobre la realidad de un abandono histórico de la salud y de las variables fuera de control, el Gobierno de Vizcarra tuvo un aparente buen inicio de su estrategia contra la pandemia, apariencia respaldada por una buena comunicación, respuesta de la población y de los medios, la valoración positiva de la comunidad internacional y una respuesta nacional política pasiva y sin liderazgos alternativos.

La gestión pública de la pandemia y las primeras medidas económicas dieron la impresión de que había un "modelo peruano" de respuesta. Se señaló que la estrategia del Gobierno era colocar los planes en la línea del modelo seguido hasta ese momento por Corea del Sur, que incluía la realización masiva de pruebas a domicilio, el seguimiento de los contagios, el uso de aplicativos y el traslado de los enfermos a los centros de salud supervisados por la autoridad en salud.
Este objetivo, si lo hubo, no fue documentado y tampoco se cumplió. El Gobierno era consciente de que la tasa de pruebas de descarte era aún baja, de 800 diarias en promedio, con una tasa más baja de pruebas fuera de la capital. Al 25 de marzo de 2020 se hicieron 8,042 pruebas moleculares y al 8 de abril 23,255.

Con ese propósito el gobierno dispuso la compra de 1 millón 600 mil pruebas; un primer lote de ellas fue distribuido en todo el país, a partir de lo cual se inició el aumento de las pruebas el 7 de abril. Las promesas del Gobierno de que 250 equipos se desplazarían a los domicilios, se ampliaría el sistema de consulta telefónica, se trasladaría los laboratorios a varias regiones del país y se instalaría un mayor número de camas y respiradores, no se cumplieron.

La cuarentena, severa y una de las más largas en el mundo, solo tenía sentido si ese tiempo se aprovechaba para mejorar los servicios de salud y realizar el rastreo de contactos. Al no implementarse estas medidas, creció la letalidad del virus: el 25 de marzo de 2020 se tenían 9 fallecidos y 480 casos $(1.87 \%$ de letalidad), y 8 de abril 121 fallecidos y 4342 casos (2.78\% de letalidad).

Las debilidades de política pública estuvieron presentes desde el inicio. Se puede apreciar ello en la revisión del Decreto Supremo N ${ }^{\circ}$ 0082020-SA del 11 de marzo de 2020, que declaró la Emergencia Sanitaria a nivel nacional por el plazo de noventa días calendario y que dictó medidas de prevención y control del COVID-19.

Las medidas dictadas pertenecen al campo de la prevención como el control de puertos, aeropuertos y puestos de entrada terrestres; la presentación de manera obligatoria la Declaración Jurada de Salud del Viajero para prevenir el COVID-19, de efecto nulo, pero que ha persistido en el tiempo; medidas en el servicio educativo, en todos los niveles; limitación de la concentración de personas en espacios cerrados y abiertos; medidas de salubridad en los establecimientos comerciales y mercados y en el transporte; y medidas de prevención en los centros laborales públicos y privados. Otras medidas dictadas entre el $11 \mathrm{de}$ marzo y el 30 de marzo confirman la respuesta exclusiva sanitaria y preventiva del Estado, probablemente sin una adecuada apreciación prospectiva de la evolución de la pandemia. 
El mencionado decreto supremo remite la estrategia a un plan, el Plan de Acción, es decir, redujo una estrategia que debió implicar una intervención multidisciplinaria a un plan del sector Salud.

El Plan fue expedido por el Decreto Supremo $\mathrm{N}^{\circ}$ 010-2020-SA y tenía por objetivo "reducir el impacto sanitario social y económico" que ocasiona la pandemia, aunque sus anexos solo consignan metas, actividades e indicadores en materia de salud. En relación a las metas, el total de 13 se refieren a actividades en salud, especialmente a la detección de casos y hospitalización. Se advierte al mismo tiempo que el sistema de salud peruano se preparó para una pandemia en una intensidad distinta a la que se experimentó rápidamente. Por ejemplo, que se proponía atender el $100 \%$ de la demanda de muestras de laboratorio y que el $100 \%$ de los contagiados reciban tratamiento clínico, o el $100 \%$ de asistencia al traslado de los pacientes. Del mismo modo, los 16 indicadores del Plan se refieren a actividades e instituciones del sector Salud, y en ellos se aprecia la ausencia de camas como variable de la hospitalización, que desde el mes de mayo de 2020 fue uno de los problemas principales que evidenció el colapso de los servicios de salud. En los citados indicadores se aprecia también la brecha digital en la autoridad en salud, al considerarse como medios de difusión afiches y banners físicos y publicidad en radios y diarios, sin tomar en cuenta la televisión y las redes sociales.

Diversas medidas adoptadas posteriormente intentaron establecer una política pública de emergencia para enfrentar la pandemia. Las normas siguientes presentan un diseño con esos propósitos, pero no se procuró la reelaboración de una estrategia multisectorial. El acceso a las actas del Consejo de Ministros podría confirmar lo que las apariciones públicas indicaban desde mediados de abril de 2020, que el Gobierno no actuó como un estado mayor central en la pandemia.

No podría desconocerse los factores fuera de control y los elementos estructurales. Estos tienen un peso sustantivo en los resultados. No obstante, los límites del Gobierno fueron al mismo tiempo impuestos y autoimpuestos, operando en esto último la cultura neoliberal en el alto nivel de gestión del Estado para resistirse o adoptar decisiones mediatizadas, uno de cuyos ejemplos más claros son las entregas de bonos, el manejo de las crisis de los desplazados internos o el apoyo al agro.

La resiliencia de la sociedad se organizó a partir de estos hechos, lo que da validez a la tesis comunitaria asociada a la de políticas públicas. No se pretende negar que en las primeras semanas hubo menos disciplina social que la esperada, lo que logró ser resuelto. No obstante, la resiliencia y la memoria operaron frente a los límites del Gobierno. La encuesta de IEP de abril planteó un asunto complejo, que el hambre puede ser más poderoso movilizador de emociones y de la razón: el $51 \%$ de peruanos le tenían más miedo al hambre que al contagio. Esta resiliencia no ha descendido con la segunda ola.

En definitiva, no fue posible establecer un modelo peruano para enfrentar a la pandemia en lo estrictamente sanitario, y sus efectos en otros ámbitos, especialmente sus efectos económicos y sociales, por una falta de desempeño eficiente de las instituciones y elecciones equivocadas o incompletas de política para la mitigación, la organización de la atención hospitalaria, la gestión de las medidas de emergencia y la compensación. El desempeño del MINSA será estudiado con detalle más adelante, pero es evidente que además de las deficiencias anotadas, no supo integrar al sistema de salud, bloqueando el aporte de ESSALUD más de una vez.

No fue solo un asunto de capacidad personal, sino de la adopción decisiones. Esta precisión no implica reconocer que Vizcarra no utilizó adecuadamente su amplio respaldo ciudadano o que ejerció un liderazgo sin las instituciones, a diferencia de varios líderes de la región que pesar de obtener una baja aprobación implementaron mejores políticas junto a las instituciones.

Por lo mismo, la crisis política que "encontró" la pandemia fue decisiva para convertir la crisis sanitaria en una gran depresión con varias crisis "grandes" y "pequeñas" por una estrategia política equívoca. En este punto, Vizcarra -y luego Sagasti, a pesar de que este tenía un menor espacio para movimientosdesplegó una presidencia solitaria y en gran medida plebiscitaria durante la pandemia. Desaprovechó durante meses la oportunidad de reimpulsar una unidad nacional básica y 
proponer un pacto mínimo, al apostar por un liderazgo sin instituciones.

En julio, cuando Vizcarra fue al Congreso para pronunciar su Mensaje a la Nación, y en las semanas siguientes, los escenarios de la pandemia eran: 1) reactivación en marcha, la pandemia bajo control y una amplia cooperación política; 2) reactivación en marcha, pandemia bajo control y baja cooperación; 3) reactivación mínima, pandemia bajo control y ausencia de cooperación; y 4) reactivación relativa, pandemia bajo control y ausencia de cooperación (De la Puente, 2020b).

El primer escenario era desafiante pero no imposible si se garantizaban reglas claras para las elecciones del 2021 y la competencia en base a algunos grandes consensos sobre las crisis. El segundo escenario, en ese momento el más probable, implicaría que los progresos de la reactivación serían menores debido a mayores tensiones, que generaría más incertidumbre y menor capacidad gubernamental para gestionar las demandas y de lo que derivaría un gobierno precario con un bajo respaldo legislativo y apoyo social a la baja. Lamentablemente, el escenario que se impuso luego de los sucesos de noviembre fue el cuarto en tránsito al tercero.

\section{Las tendencias}

La irrupción de la segunda ola del Covid-19 fue intensa y dramática; en pocas semanas los casos y muertes escalaron en un ritmo superior a la primera ola. El reconocimiento oficial fue realizado por el Gobierno el 12 de enero de 2021 cuando ya se tenían varios indicadores sanitarios al alza desde finales del mes de diciembre. La tardanza en el reconocimiento de la segunda ola se debió tanto a los disensos al interior del Gobierno en la identificación del nuevo proceso, como a la ausencia de una respuesta adecuada ante el aumento de los contagios.

La pandemia como problema nacional se agravó por la precariedad de la reacción del Estado y el fracaso de la política seguida por el Gobierno de Vizcarra sobre la adquisición de la vacuna contra el coronavirus, un pendiente que el Gobierno del presidente Sagasti encaró con sus propias deficiencias y resolvió hasta el cierre del período estudiado.
La sensación de la opinión pública al iniciarse la segunda ola fue de resiliencia frente al colapso del Estado para la provisión de servicios hospitalarios. Con mayor intensidad que en la primera ola, los peruanos esperaban muy poco del Estado y asumían sus decisiones de prevención ante los contagios y la búsqueda de medios de vida.

La segunda ola fue una nueva ola, y no exclusivamente por la progresión agresiva de los contagios; también por incremento de las omisiones del Estado, en un contexto de falta de recursos, equipo, recursos humanos y liderazgo.

Desde el inicio de la segunda ola, la hospitalización por Covid-19 alcanzó el nivel que experimentó en mayo de 2020 en dos meses después de iniciada la pandemia. No había consenso sobre la agresividad de los contagios. El Ministerio de Salud (MINSA) refirió oficialmente el 8 de enero de 2021 que la llamada "variante inglesa" había llegado al Perú ${ }^{17}$, en tanto que otros especialistas señalaron la existencia de "cepas peruanas" que, el igual que las que provienen de Gran Bretaña y supuestamente de otros países. No obstante, era innegable la rápida progresión de los contagios, la escasez de camas, oxígeno y de camas UCI.

No se dudaba de la rápida progresión de los contagios y la saturación de los servicios de salud. A diferencia de la primera ola, la segunda encontró al Gobierno sin posibilidades de formular una respuesta aún mínima como en los meses marzo-mayo de 2020, sin recursos fiscales y con un bajo nivel de acatamiento de las restricciones por parte de las personas en la segunda cuarentena dictada en febrero de 2021.

La reacción del Gobierno se llevó a cabo estrictamente en el ámbito hospitalario, en tanto no se realizaron esfuerzos apreciables en el rastreo de contactos y otras medidas de prevención. Las tensiones entre la salud y la economía y las capacidades institucionales determinaron un deplorable cuadro que se agravó en febrero a pesar de la segunda cuarentena.

La segunda ola no fue exclusiva del Perú, pero a diferencias de varios países de la región, el Perú no contó con un modelo para encararla. El nivel de contagios debió conducir a adopción

17 https://canaln.pe/actualidad/covid-19-confirman-primercaso-variante-britanica-virus-peru-n429785 
de medidas más audaces, pero esto no sucedió por la falta de fuerza del Estado para imponerlas, la resistencia de los ciudadanos y de las empresas a acatar las medidas actuales, y una visible falta de liderazgo en el Gobierno y el sector Salud.

La segunda ola fue también nueva respecto a la desprotección social. El gobierno dispuso un bono "desuniversalizado". El reparto de alimentos a través del Ministerio de Defensa fue lento y aunque fue un avance la aprobación de la Intervención Temporal Hambre Cero $^{18}$, la falta de recursos se convirtió en la principal limitación de la cualquier política de compensación en la segunda ola. Tampoco se contó con la aprobación de nuevos programas de apoyo empresarial en la dimensión de los ejecutados durante la primera ola.

La posición oficial del gobierno respecto a la falta de recursos fiscales fue objeto de controversia. Se estimaba que el gobierno tenía depósitos por una suma de 71 millones de soles en el sistema bancario, mientras el BCR sostenía que existía un nivel significativo de recursos públicos que constituían el $12 \%$ del PBI (BCR, 2021b). El cambio de la conducción en el Ministerio de Economía y Finanzas (MEF) dio paso a una política de austeridad que no fue desafiada por el resto del Gobierno.

El Documento Técnico aprobado en noviembre de 2020 por MINSA de preparación y repuesta ante una probable segunda ola ${ }^{19}$ estimaba que en Lima la población contagiada alcanzaría en la segunda ola el $40 \%$ y en las regiones más afectadas el $75 \%$. No obstante, los efectos fueron mayores, y las necesidades superaron las expectativas. El MINSA preveía que la segunda ola podría causar entre 14 y 19 mil muertos según el tipo de escenario, es decir, "leve", "más probable", y "peor". La propuesta del Documento Técnico recomendaba que debería reducirse el riesgo previniendo la movilización de personas para fiestas de fin de año, lo que no se logró.

Las previsiones de la Defensoría del Pueblo advertían el 24 de enero de 2021 que, si la segunda ola empeora en un mes, el oxígeno no alcanzará ${ }^{20}$. A fines de enero de acuerdo

\footnotetext{
18 R.M. N ${ }^{\circ}$ 031-2021-MIDIS

19 R.M. N 928-2020/MINSA

20 https://saludconlupa.com/entrevistas/si-la-segunda-olaempeora-en-un-mes-el-oxigeno-no-alcanzara/
}

a las cifras de la Superintendencia Nacional de Salud, se estaba al 20\% de los 805 mil metros cúbicos de oxígeno que se necesita diariamente, aunque de ingreso al nivel más alto de la pandemia se requerirían 3.5 millones de metros cúbicos diariamente.

La segunda ola impactó en la política peruana más allá de lo estrictamente epidemiológico. Se agregó a la crisis económica y sus efectos en ingresos, empleos e inseguridad alimentaria $\mathrm{y}$ en ese punto las tensiones entre salud $\mathrm{y}$ economía; a la crisis política tocadas por los eventos de noviembre; y al proceso electoral que había evadido la pandemia como un elemento del corto plazo electoral, y al que los candidatos a las elecciones empezaron a referirse con mayor frecuencia. La posibilidad de que se postergaran las elecciones del 11 de abril para evitar más contagios terminó por reagrupar la política peruana en torno al Covid-19 como su variable más decisiva.

Una segunda ola sin respuesta en el terreno epidemiológico y sin políticas de compensación ofreció el cuadro de la pandemia como un elemento incidió en el deterioro de la cohesión social con efectos más allá de los estrictamente sanitario. No obstante, se trasformó en un movilizador de la política en sentido alternativo a lo deseado, es decir, contra el Estado o sin el Estado. El fracaso del Gobierno de Vizcarra en la compra oportuna de la vacuna renovó la discusión sobre los límites del Estado, la falta de liderazgo y la eficacia del Gobierno. Para la opinión pública, en la encuesta Ipsos Perú de enero de 2021, los principales responsables eran el gobierno del presiente Vizcarra y el Congreso. Aún no se sabía entonces la vacunación secreta de Vizcarra.

La opinión pública se movilizó de modo individual en relación a la segunda ola; predominó en ella la idea de que debería de encarar su seguridad en términos personales, sin la presencia del Estado. De hecho, la falta de un compromiso personal de los ciudadanos con las medidas sanitarias debe interpretarse también como la extensión de la política de que "cada quien baila con su pañuelo". De otro modo no se entiende que en la encuesta de Ipsos Perú de enero de 2021, el 67\% consideraba que los contagios aumentarán, que en la misma encuesta el $48 \%$ señalaba que no se vacunará y solo el $32 \%$ proponía que se implemente más restricciones. Un $36 \%$ de 
personas señalaba que las restricciones deben disminuir porque las personas tienen que saber cuidarse solas. La encuesta fue publicada antes de que el Gobierno disponga la cuarentena.

Algunos análisis consideran que este temperamento de la opinión pública correspondía a una poderosa campaña organizada por sectores ultraconservadores negacionista en relación al Covid. Esta campaña existió, pero lo más probable es que reflejó especialmente una brecha abierta entre el relato público y oficial sobre la pandemia, frecuentemente incoherente entre el discurso y la práctica, y la realidad de un país resiliente que enfrenta sin mayores ayudas esta segunda y nueva ola de la pandemia.

La pandemia, la vacuna y la crisis económica impactó el escenario electoral y obligó a la mayoría de partidos a modificar su relato electoral que pretendía centrarse en las promesas de mediano y largo plazo, orillando los asuntos de la gran depresión peruana actual.

En la parte final del período estudiado, los partidos se movilizaron en función de la pandemia. Propugnaron que la vacuna llegue a tiempo y sea suministrada a todos, demandaron una política de cuidados, cuestionaron los retrasos y la falta de cobertura de los sistemas sanitarios y, en algunos casos, -como el expresidente Vizcarra- propusieron la postergación de las elecciones. Es probable que las propuestas para postergar las elecciones no se formularan estrictamente en atención a la pandemia, sino que escondían una estrategia electoral; aun así, la pandemia se convirtió en un elemento decisivo a partir de la cual se adoptaron decisiones.

En términos institucionales las posibilidades de postergar las elecciones presentaban más problemas que soluciones. Al margen de la conveniencia política para algún partido, el sistema peruano no ha diseñado una ruta legal que permita la postergación de las elecciones. Estas son convocadas obligatoriamente por el presidente de la República por mandato constitucional, sin que tenga prerrogativas para postergarlas, proponer su postergación o impedirlas. En este último caso, inclusive, el presidente puede ser objeto de una acusación constitucional. La otra opción, que el Congreso apruebe una ley que postergue las elecciones, puede seguir el mismo razonamiento debido a que el Parlamento no tiene en el diseño constitucional peruano prerrogativas para convocar ni para postergar las elecciones, y su papel se reduce a aprobar leyes vinculadas a la reglamentación de los procesos electorales y reformas constitucionales sobre los organismos electorales o los procesos electorales.

\section{CONCLUSIONES}

\section{Efectos intensos inmediatos}

Como sucedió con la primera ola, la progresión de la segunda ola tuvo efectos intensos y dramáticos sin que el Estado peruano pueda ofrecer una respuesta de mitigación mínima. En el terreno hospitalario, la saturación de los servicios de salud ocasionó que la segunda ola sea más larga y letal de lo previsto con las consecuencias ya señaladas. La segunda ola confirma la imposibilidad del Gobierno de establecer medidas nuevas o con mayores restricciones, en una dinámica donde los ciudadanos tampoco se muestran dispuestos a aceptarlas o acatarlas. No se aprecia que el cuadro señalado generara una intensa conmoción política y social, aunque el Congreso incidió en los errores y retrasos del gobierno, con algunos efectos institucionales. Esta perspectiva cambió en el siguiente período, con el escándalo de las vacunas.

\section{El fin del consenso neoliberal y un consenso 2.0 .}

Es cierto que la pandemia ha diluido el débil consenso social que quedaba del neoliberalismo. Este agotamiento no fue súbito. El neoliberalismo no fue fecundo en los últimos años; sus políticas de reactivación para volver al punto de crecimiento del período 2004-2013 no funcionaron a pesar de por lo menos cuatro delegaciones de facultades y casi 200 decretos legislativos. Pudo ser distinto; el mercado peruano era uno de los más sólidos y ágiles de América Latina en un país donde el llamado "modelo" tuvo efectos en la reducción de 35 puntos de pobreza y la rebaja de otros indicadores sociales luego de innovaciones exigidas, especialmente en materia de protección social. Su conservadurismo, tanto político como económico, impidió el gran salto hacia reformas sentidas y ahora resentidas. La clave son las ideas. Con matices cada vez menos perceptibles, la reactivación actual se nutre del canon neoliberal agotado. La gran 
depresión ha reducido el efecto de las políticas públicas y discursos oficiales, entre ellos del pensamiento económico predominante, que carece de un programa para salir de la crisis. Aun así, no se puede descartar un nuevo consenso neoliberal como resultado de las elecciones de 2021 en atención a que el país demanda cambio y unidad, un desafío que los grupos políticos y de presión no están dispuestos a ofrecer en conjunto. En ese contexto, el relanzamiento neoliberal es una opción que no debe subestimarse.

\section{La épica humanista}

La pandemia ha implicado nuevos reconocimientos de derechos y de deberes públicos. Desde marzo de 2020 se han emitido miles de normas. Es un derecho de crisis, producción inédita y extraordinaria en por lo menos seis grandes áreas: 1) emergencia política y sanitaria; 2) salud pública; 3) protección social y derechos; 4) reactivación de la economía; 5) acceso a servicios esenciales; y 6) control. El Perú ha iniciado una nueva generación de derechos económicos y sociales y de obligaciones que se impone el Estado, un efecto que trascenderá la pandemia. Las normas aprobadas pueden dividirse en tres grandes grupos. El primero se refiere a la contención en materia social, destacando las trasferencias monetarias directas y la seguridad alimentaria. Un segundo grupo se refiere al reconocimiento formal de derechos de sectores cuya vulnerabilidad se ha agravado con la pandemia, es decir, los trabajadores públicos y privados, los adultos mayores, las personas con discapacidad y los estudiantes. Un tercer grupo de normas se refiere a la atención de crisis humanitarias que la pandemia expone, como la situación de los penales, de los pueblos originarios y la violencia contra la mujer y el núcleo familiar.

Es probable que la falta de arreglos institucionales dificulte la ejecución adecuada de estos avances. Es reconocible no obstante el esfuerzo en materia de protección social. La producción de normas es acompañada del establecimiento de bases de datos, plataformas, reconocimiento de beneficiarios y ampliación de cobertura de programas existentes, a pesar de las dificultades propias de la pandemia y de que gran parte del trabajo se realizase de modo virtual.

\section{Economía y pobreza como nuevos ejes públicos.}

Esta nueva realidad operó contra el predominio de los procesos anticorrupción y la reforma política del periodo 2016-2019. La crisis fue más severa de lo estimado inicialmente y pocas semanas licuó 18 años de la formación del mayor auge económico de nuestra República, un impacto en la emoción colectiva no procesó. La crisis será más extensa en el tiempo y más profunda que lo esperado. Su volumen fue determinante en el juego político de cara a las elecciones porque luego de varios meses de pandemia se asumió que no habrá retorno a la normalidad, lo que sin embargo todavía era una apuesta oficial del Gobierno y de una parte del liderazgo empresarial. Un informe del Programa Mundial de Alimentos (WFP, por sus siglas en inglés), sobre el impacto del Covid-19 en América Latina concluía que, a mayo de 2020, un promedio de 16 millones de personas sufría de inseguridad alimentaria en el Perú; de ellos, 3.5 millones vivían en inseguridad alimentaria severa, en tanto el $61 \%$ recurrían al uso de estrategias de sobrevivencia que afectan el consumo de alimentos. El mismo estudio reporta que $20 \%$ de los encuestados declararon que no consumían ningún alimento o una sola comida en las 24 horas anteriores, con una mayor proporción entre los encuestados urbanos. El PMA realizó otra investigación agosto de 2020 y a inicios de 2021, indicando que entre enero y febrero de 2021 "en el Perú existían 4 millones que padecían inseguridad alimentaria severa, es decir que pasaban un día o más sin comer. Si bien es cierto que esta cifra -el $12 \%$ de la población- es menor en 500 mil a la registrada en la anterior medición del PMA en agosto pasado (4.5 millones, el 13.7\% de la población), es un dato alarmante que expone con realismo y crudeza el efecto de la pandemia y la crisis económica". Luego, el Instituto Nacional de Estadística e Informática (INEI) reportó en mayo de 2021 que el año 2020, "la pobreza monetaria afectó al $30.1 \%$ de la población del país, incrementándose en 9.9 puntos porcentuales en comparación con el año 2019" y que "en los últimos cinco años la población en situación de pobreza aumentó en 8.3 puntos porcentuales". 


\section{Los limites del Estado, impuestos y autoimpuestos}

Los límites del Estado, impuestos y autoimpuestos, afectan la toma de decisiones y su eficacia en la gran depresión. La idea predominante en marzo de 2020 de que "todo cambiará" en el sentido que cambiará para bien, o que la nueva normalidad será necesariamente nueva, es muy debatible especialmente cuando el cambio asume la forma de una gran depresión. La pandemia y las otras crisis que forman parte de la gran depresión han transformado la política peruana, aunque en sentido distinto a lo imaginado. Los cambios fueron progresivos y regresivos y no todo ha cambiado, y menos en lo que se suponía. Se esperaba una gran innovación y una crisis económica menos grave, y en cambio se tuvo poca innovación y una gran depresión. El 15 de marzo de 2020 ingresamos a la primera cuarentena con incertidumbre, unidad y cooperación, es decir con una promesa, y en febrero de 2021 se inició una segunda cuarentena con desconfianza, polarización y desprotección.

La política careció de una respuesta para la gigantesca crisis; tuvo relatos algunos con más peso que otros, como la reactivación y la defensa de la vida, pero careció de agenda, es decir, de una hoja de ruta más o menos ordenada. Aún con cuestionamientos, las instituciones económicas (MEF, BCR, SUNAT) asumieron la gestión de la gran depresión con mayor claridad que las agencias llamadas a la dirección política, una separación entre economía y política con predominio absoluto de la primera.

El límite del Estado y el Gobierno fue un punto de llegada autoimpuesto; presentó dos planos, un límite operativo y otro estratégico. Respecto a lo primero, la gran depresión se compuso a su vez de varias crisis sectoriales y territoriales que pugnaban por salidas parciales y establecían una tendencia de desorden que el Estado no atendió en su transversalidad. Un rasgo de la ausencia de agenda fue la lenta reapertura del Estado, en menor intensidad que la economía. En este punto se ubicó una parte de los retrasos y las omisiones para abordar la atención de servicios esenciales y seguridad, supervisión, control, regulación, entre otros. En el período estudiado, el Estado peruano pudo haber operado a poco más del $40 \%$ de sus competencias. Respecto al límite estratégico, una oportunidad para los cambios en el marco de una normalidad superior previa a la pandemia fue el diálogo y los acuerdos en la forma expresa de un Nuevo Acuerdo Nacional que Vizcarra y Sagasti cada uno en su momento, subestimaron.

\section{FUENTES DE INFORMACIÓN}

BCRP(2020a). Reporte de inflación junio 2020. Recuperado de: https://www.bcrp.gob.pe/docs/ Publicaciones/Reporte-Inflacion/2020/junio/ reporte-de-inflacion-junio-2020.pdf

BCRP (2020b). Reporte de inflación de diciembre 2020. Recuperado de: https://www. bcrp.gob.pe/docs/Publicaciones/ReporteInflacion $/ 2020 / \mathrm{diciembre/reporte-de-}$ inflacion-diciembre-2020.pdf

Chul.Han, B. (21 de marzo de 2020). La emergencia viral y el mundo de mañana. Byung-Chul Han, el filósofo surcoreano que piensa desde Berlín. El País. Recuperado de:

https://elpais.com/ideas/2020-03-21/laemergencia-viral-y-el-mundo-de-mananabyung-chul-han-el-filosofo-surcoreano-quepiensa-desde-berlin.html

Defensoría del Pueblo (2020). Supervisión a los servicios brindados por la Línea 100 durante el estado de emergencia sanitaria a raíz del COVID-19. Recuperado de:

https://www.defensoria.gob.pe/wp-content/ uploads/2020/10/Informe-de-ADM-019L\%C3\%ADnea-100-VF.pdf

De la Puente, J. (19 de noviembre de 2020a). La revolución del bicentenario. La República.

Recuperado de: https://larepublica.pe/ opinion/2020/11/19/1a-revolucion-delbicentenario/

De la Puente, J. (19 de abril 2020b). Primeros apuntes de una coyuntura crítica. La República. Recuperado de https://juandelapuente.com/ primeros-apuntes-de-una-coyuntura-critica/

De la Puente, J. (8 de agosto de 2020c). Nuevo gabinete y escenarios 2020-2022. La República. Recuperado de: https://juandelapuente.com/ nuevo-gabinete-y-escenarios-2020-2022-lamitad-mas-uno/ 
INEI (2019). Perú: encuesta demográfica y de salud familiar 2019. Nacional y departamental. Recuperado de:

ht tps://www.inei.gob.pe/media/ MenuRecursivo/publicaciones_digitales/Est/ Endes2019/Libro.pdf

Lowy Instituto (2021). Índice de rendimiento de Covid. Recuperado de: https:// interactives.lowyinstitute.org/features/covidperformance/\#overview

PNUD Perú (2012). Informe de cumplimiento de los objetivos de desarrollo del milenio. Recuperado de:

file: / / U sers / juan / Down loads / ODM\%2520informe\%25202008\%20(1).pdf

PNUD Perú (2019). El reto de la igualdad, Recuperado de: https://www.pe.undp. org/content/peru/es/home/presscenter/ articles/2019/el-reto-de-la-igualdad.html

Sierra, N. (2020). Crónica de un colapso anunciado. El Covid y el derrumbe del Capitalismo. En Boletín Académico Sociología y Política Hoy. Recuperado de:

https://www.clacso.org/wp-content/ u p 1 o a d s / $2020 / 09 / \mathrm{BOLET} \mathrm{I} \mathrm{N} \mathrm{-}$ SOCIOLOGI\%CC\%81A-4-WEB-finalsptb-020.pdf
Tanaka, M. (2020). Coronavirus y respuestas de política (2). En Crónicas del gran encierro. Recuperado de: https://iep.org.pe/wp-content/ uploads $/ 2020 / 06 / \mathrm{Cr} \% \mathrm{C} 3 \% \mathrm{~B} 3$ nica-del-GranEncierro-1.pdf

Touraine, A. (14 de mayo de 2020) Hemos pasado de una sociedad masculina a una femenina. Diario Uchile. Recuperado de:

https://radio.uchile.cl/2020/04/14/alaintouraine-hemos-pasado-de-una-sociedadmasculina-a-una-femenina/

Trivelli, C. (2020). Conexión mínima para atender la emergencia. En Crónicas del gran encierro. Recuperado de: https://iep.org.pe/wpcontent/uploads/2020/06/Cr\%C3\%B3nicadel-Gran-Encierro-1.pdf

Velázquez, Marcel. (2020). Hijos de la peste. Una historia de las epidemias en el Perú. Taurus.

UIS (2014). Asumiendo el concepto de salud. En Revista de la Universidad Industrial de Santander, Salud $N^{o}$ 46. Recuperado de: $\quad$ https://www.redalyc.org/articulo. oa? $\mathrm{id}=343838645001$ 